\title{
Lipolytic System of the Tomato Pathogen Fusarium oxysporum f. sp. Iycopersici
}

\author{
Gustavo Bravo-Ruiz, Carmen Ruiz-Roldán, and M. Isabel G. Roncero \\ Departamento de Genética, Universidad de Córdoba and Campus de Excelencia Agroalimentario (ceiA3), E-14071 \\ Córdoba, Spain
}

Submitted 22 March 2013. Accepted 18 May 2013.

The lipolytic profile of Fusarium oxysporum f. sp lycopersici was studied by in silico search and biochemical enzyme activity analyses. Twenty-five structural secreted lipases were predicted based on the conserved pentapeptide GlyX-Ser-X-Gly-, characteristic of fungal lipases, and secretion signal sequences. Moreover, a predicted lipase regulatory gene was identified in addition to the previously characterized $c t f 1$. The transcription profile of thirteen lipase genes during tomato plant colonization revealed that lip1, lip3, and lip22 were highly induced between 21 and $96 \mathrm{~h}$ after inoculation. Deletion mutants in five lipase genes (lip1, lip2, lip3, lip5, and lip22) and in the regulatory genes ctf 1 and $c t f 2$ as well as a $\Delta c t f 1 \Delta c t f 2$ double mutant were generated. Quantitative reverse transcription-polymerase chain reaction expression analyses of structural lipase genes in the $\Delta c t f 1, \Delta c t f 2$, and $\Delta c t f 1 \Delta c t f 2$ mutants indicated the existence of a complex lipase regulation network in $F$. oxysporum. The reduction of total lipase activity, as well as the severely reduced virulence of the $\Delta c t f 1, \Delta c t f 2$, and $\Delta c t f 1 \Delta c t f 2$ mutants, provides evidence for an important role of the lipolytic system of this fungus in pathogenicity.

Lipases have a unique role due to their potential ability to hydrolyze plant cuticular waxes. In addition, various types of lipids occur in plant cells, the most important being phospholipids and glycolipids, both of which, along with proteins, are the main constituents of plant cell membranes. Oils and fats are found in many cells, especially in seeds, in which they function as energy storage compounds. These components may be the target of lipolytic enzymes such as lipases and phospholipases, which hydrolyze fatty acids from the lipid molecule. Plant-pathogenic fungi produce an array of extracellular lytic enzymes that enable them to penetrate and infect the host tissue (Rogers et al. 1994; Walton 1994) and are collectively called cell wall-degrading enzymes (CWDE). These enzymes may contribute to pathogenesis by degrading waxes, cuticle, and cell walls, thus aiding tissue invasion and pathogen dissemination (Di Pietro et al. 2009). Furthermore, they can act as elicitors of host defense reactions and might also play a nutritional role during certain stages of the fungal life cycle.

Corresponding author: M. I. G. Roncero; E-mail: roncero@uco.es; Telephone: (+34) 957218981; Fax (+34) 957212072.

* The $\boldsymbol{e}$-Xtra logo stands for "electronic extra" and indicates that eleven supplementary figures and two supplementary tables are published online.

(C) 2013 The American Phytopathological Society
Lipases (triacylglycerol acylhydrolases) are lipolytic serine esterases acting on the carboxyl ester bonds present in acylglycerols to generate organic acids and glycerol (Jaeger and Eggert 2002). Fungal lipases and esterases may be involved in providing carbon sources during plant cell-wall degradation, as well as in adhesion to and penetration of the plant surface. Some reports exist on the role of secreted fungal lipases in plant pathogenicity. A purified lipase from Alternaria brassicicola was found to cross-react with antibodies against a Botritys cinerea lipase, and addition of the antilipase antibodies to a conidial suspension of Alternaria brassicicola resulted in a $90 \%$ reduction of blackspot lesions on intact cauliflower leaves but not on leaves from which the surface wax had been removed (Berto et al. 1999). A gene encoding a secreted lipase from Fusarium solani f. sp. pisi was highly induced by lipidic substrates, repressed by glucose, and expressed in planta at different times after inoculation (Nasser Eddine et al. 2001). A secreted lipase of $B$. cinerea was induced during early stages of infection (Commenil et al. 1998). When specific antilipase antibodies were added to a conidial suspension of $B$. cinerea, lesion formation was completely suppressed (Commenil et al. 1999). However, targeted disruption of the gene lipl did not affect virulence of B. cinerea (Reis et al. 2005). Even double mutants that lacked both lipl and the cutinase gene cutA and were largely devoid of extracellular esterase activity retained full virulence on various host plants (Reis et al. 2005). Pathogenicity of Burkholderia glumae in rice is regulated by quorum sensing of acyl homoserine lactone through LipA, a secreted lipase. Burkholderia glumae lipA mutants were no longer pathogenic to rice, indicating that the lipase is an important virulence factor (Devescovi et al. 2007). The pathogenic fungus $F$. graminearum is able to secrete various lipases under appropriate growth conditions and during plant infection (Feng et al. 2005; Nguyen et al. 2010; Paper et al. 2007; Voigt et al. 2005). Two extracellular lipases have been investigated in $F$. graminearum. FGL1 was the first described fungal extracellular lipase associated with virulence (Voigt et al. 2005), but disruption of the extracellular lipase encoded by the LIPl gene involved in utilization of saturated fatty acids, showed no effect on virulence during colonization of wheat heads (Feng et al. 2005). Expression of FGL1 is regulated by the mitogenactivated protein kinase Gpmk1 (Salomon et al. 2012). Constitutive expression of FGL1 in the $\Delta g p m k 1$ mutant was sufficient to partially restore pathogenicity to the mutant (Salomon et al. 2012).

On the basis of its annotated genome, four additional secreted lipases sharing motifs with FGL1 and other fungal lipases were identified in F. graminearum (Nguyen et al. 2010). They contain a putative lipase domain of five amino acids (pentapeptide) -Gly-X-Ser-X-Gly-. This domain contains a Ser, which 
forms part of the highly conserved catalytic triad Ser-Asp/GluHis (Blow 1992; Lowe 1992; Shen et al.1998).

One of the first plant signal molecules identified as an inducer of the fungal pathogenicity response is the cutin monomer. In a series of pioneering experiments, Woloshuk and Kolattukudy (1986) showed that cutin monomers released from the plant cuticle trigger rapid upregulation of cutl, a gene encoding an extracellular cutinase in the pea pathogen $F$. solani f. sp. pisi (Nectria haematococca). Two lines of evidence indicate that cutl acts as a virulence factor. Targeted disruption of the cutl gene reduced virulence on the intact host surface (Rogers et al. 1994), while heterologous expression of cutl in the wound-infecting pathogen Mycosphaerella spp. conferred the ability to infect the intact plant without the need of a wound (Dickman et al. 1989). Regulation of fungal cutinases has been extensively studied in $F$. solani $\mathrm{f}$. sp. pisi. Transcriptional induction of cutl is strongly induced by cutin monomers and mediated by the zinc finger transcription factor CTF $1 \alpha(\mathrm{Li}$ and Kolattukudy 1997; Li et al. 2002). In Aspergillus nidulans, two proteins with homology to CTF $1 \alpha$, farA and $\operatorname{far} B$, regulate the expression of genes implicated in metabolism of shortchain and long-chain fatty acids (Hynes et al. 2006). FarA and FarB bind in vitro to the same core DNA element CCGAGG that mediates binding of the cutinase transcription factor CTF1 $\alpha$ (Li and Kolattukudy 1997; Li et al. 2002), suggesting that transcriptional regulation of fatty acid metabolism may be broadly conserved in fungi. In the tomato vascular wilt fungus $F$. oxysporum f. sp. lycopersici, mutants carrying a $\Delta c t f 1$ lossof-function allele failed to activate extracellular cutinolytic activity and expression of the cutl and lipl genes, encoding a putative cutinase and lipase, respectively, on inducing substrates (Martínez Rocha et al. 2008).

F. oxysporum is a soilborne pathogen that causes economically important losses on a wide variety of crops and infects its host plants strictly through the roots (Di Pietro et al. 2003). During penetration and root colonization, $F$. oxysporum secretes a battery of CWDE such as polygalacturonases, pectate lyases, xylanases, and cutinases (Di Pietro and Roncero 1998; García-Maceira et al. 2000, 2001; Gómez-Gómez et al. 2001, 2002; Huertas-González et al. 1999; Martínez-Rocha et al. 2008; Ruiz et al. 1997; Ruiz-Roldán et al. 1999), thus representing an excellent model to study the role of lipases in fungal root pathogens. Here, we present a biochemical and genome-wide characterization of the F. oxysporum f. sp. lycopersici lipase profile by targeted gene disruption and enzyme activity analyses, providing evidence for the importance of the lipolytic system of this fungus in pathogenicity on tomato plants.

\section{RESULTS}

Sequence analysis and phylogenetic relationships
of $F$. oxysporum lipase and lipase-regulatory genes.

In order to characterize the lipolytic system of $F$. oxysporum f. sp. lycopersici (wild-type strain 4287), we performed a search of the genome sequence database (Broad Institute website), with the deduced amino acid sequences of the $F$. graminearum lipase genes FGL1 and FGL5 (Nguyen et al. 2010; Voigt et al. 2005) and the $F$. solani lipase regulatory genes ctfl $\alpha$ and $c t f l \beta$, respectively ( $\mathrm{Li}$ and Kolattukudy 1997; Li et al. 2002). Twenty five predicted structural lipase genes were identified, including lipl (previously identified by Martínez Rocha et al. 2008), lip1.2, lip2, lip3, lip4, lip5, lip6, lip7, lip8, lip9, lip10, lip11, lip12, lip13, lip14, lip15, lip16, lip17, lip18, lip19, lip20, lip21, lip22, lip23 and lip24, as well as two predicted lipase regulatory genes, ctfl (previously described by Martínez Rocha and associates 2008) and ctf2. Selection criteria were highly conservative, requiring values equal to or less

Table 1. Features of Fusarium oxysporum structural and regulatory lipase encoding genes and their deduced proteins

\begin{tabular}{|c|c|c|c|c|c|c|c|c|c|c|c|c|c|c|}
\hline \multirow[b]{2}{*}{ Locus ID } & \multirow[b]{2}{*}{ Gene } & \multicolumn{9}{|c|}{ Gene description } & \multicolumn{4}{|c|}{ Protein description $^{\mathrm{b}}$} \\
\hline & & Chromosome & Length $^{a}$ & ORF ${ }^{a}$ & Exon I & Exon II & Exon III & Exon IV & Exon V & Exon VI & Length & MW & pI & S. P. \\
\hline FOXG_07600 & lipl & 4 & 1,136 & 1041 & $1-91$ & $138-303$ & $353-1136$ & & & & 347 & 36.55 & 6.38 & $1-16$ \\
\hline FOXG_07142 & $\operatorname{lip} 1.2$ & 6 & 1,169 & 738 & $1-79$ & $127-292$ & $465-795$ & $852-1169$ & & & 246 & 32.55 & 5.23 & $1-19$ \\
\hline FOXG_00147 & lip2 & 1 & 1,218 & 1218 & $1-1218^{c}$ & & & & & & 406 & 45.18 & 5.43 & $1-17$ \\
\hline FOXG_13474 & lip3 & 12 & 1,835 & 1620 & $1-200$ & $253-415$ & $474-708$ & $761-1701$ & $1755-1835$ & & 540 & 58.49 & 5.13 & $1-25$ \\
\hline FOXG_02646 & lip4 & 5 & 1,778 & 1686 & $1-1572$ & $1662-1778$ & & & & & 562 & 60.77 & 7.64 & $1-24$ \\
\hline FOXG_09554 & $\operatorname{lip} 5$ & 11 & 1,605 & 1602 & $1-1605$ & & & & & & 534 & 57.93 & 8.99 & $1-18$ \\
\hline FOXG_05802 & lip6 & $2 \mathrm{a}$ & 1,680 & 1677 & $1-1680$ & & & & & & 559 & 61.27 & 6.06 & $1-18$ \\
\hline FOXG_07635 & lip7 & 4 & 1,667 & 1614 & $1-584$ & $635-1667^{\mathrm{c}}$ & & & & & 538 & 58.60 & 8.68 & $1-19$ \\
\hline FOXG_08230 & lip8 & $2 \mathrm{a}$ & 1,752 & 1596 & $1-338$ & $391-521$ & $572-828$ & $880-1752$ & & & 532 & 93.93 & 6.40 & $1-19$ \\
\hline FOXG_09590 & lip 9 & 11 & 1,658 & 1602 & $1-225$ & $279-1658$ & & & & & 534 & 58.74 & 7.96 & $1-20$ \\
\hline FOXG_09686 & lip10 & 11 & 1,865 & 1809 & $1-537$ & 591-1865 & & & & & 603 & 65.19 & 5.62 & $1-21$ \\
\hline FOXG_09995 & lip11 & 11 & 2,521 & 1656 & $1-261$ & $310-538$ & $588-1282$ & $1943-2071$ & $2128-2313$ & 2364-2521 & 552 & 60.17 & 5.64 & $1-21$ \\
\hline FOXG_10043 & lip12 & 11 & 1,656 & 1653 & $1-1656$ & & & & & & 551 & 61.29 & 8.93 & $1-20$ \\
\hline FOXG_11103 & lip13 & 1 & 1,755 & 1752 & $1-1755$ & & & & & & 584 & 63.03 & 5.09 & $1-19$ \\
\hline FOXG_12933 & lipl4 & 9 & 2,337 & 2334 & $1-2337$ & & & & & & 778 & 88.13 & 5.65 & $1-19$ \\
\hline FOXG_13336 & lip15 & 12 & 1,979 & 1623 & $1-105^{\mathrm{c}}$ & $159-226^{\mathrm{c}}$ & $296-710$ & $844-982$ & $1039-1126^{\mathrm{c}}$ & $1172-1979^{\mathrm{c}}$ & 541 & 59.00 & 5.28 & $1-17$ \\
\hline FOXG_14499 & lip16 & 12 & 1,686 & 1683 & $1-1686$ & & & & & & 561 & 62.60 & 6.20 & $1-25$ \\
\hline FOXG_14512 & lip17 & 12 & 1,624 & 1569 & $1-460$ & $513-1624$ & & & & & 523 & 57.24 & 8.66 & $1-20$ \\
\hline FOXG_15258 & lip18 & 5 & 1,634 & 1584 & $1-553$ & 601-1634 & & & & & 528 & 57.30 & 8.14 & $1-17$ \\
\hline FOXG_15259 & lip19 & 5 & 1,677 & 1473 & $1-993$ & $1050-1177$ & $1228-1325^{\mathrm{c}}$ & $1373-1459^{c}$ & $1511-1677$ & & 491 & 53.80 & 9.37 & $1-23$ \\
\hline FOXG_15569 & lip20 & 15 & 1,074 & 1074 & $1-1074$ & & & & & & 358 & 38.09 & 5.59 & $1-20$ \\
\hline FOXG_16028 & lip21 & Unpositioned & 1,074 & 1074 & $1-1074$ & & & & & & 358 & 38.16 & 5.44 & $1-20$ \\
\hline FOXG_16927 & lip22 & 13 & 1,347 & 1347 & $1-1347$ & & & & & & 449 & 48.12 & 5.58 & $1-20$ \\
\hline FOXG_17012 & lip23 & Unpositioned & 1,800 & 1704 & $1-285$ & $335-364$ & $412-1800$ & & & & 568 & 62.19 & 9.09 & $1-21$ \\
\hline FOXG_17501 & lip24 & Unpositioned & 1,569 & 1566 & $1-1569$ & & & & & & 522 & 56.69 & 9.25 & $1-24$ \\
\hline FOXG_04196 & $c t f 1$ & 4 & 3,176 & 2709 & $1-137$ & $198-222$ & $416-433$ & $527-660$ & $727-3057$ & $3110-3176$ & 903 & 100.77 & 6.93 & NO \\
\hline FOXG_01610 & $c t f 2$ & 5 & 3,200 & 2658 & $1-240$ & $321-349$ & $514-755$ & $1001-1512$ & $1563-3200$ & & 886 & 98.61 & 6.45 & NO \\
\hline
\end{tabular}

${ }^{a}$ Measured in nucleotides. ORF $=$ open reading frame.

${ }^{\mathrm{b}}$ Amino acid length; $\mathrm{MW}=$ molecular weight, measured in kiloDaltons;pI = isoelectric point; and S.P. = signal peptide.

${ }^{c}$ Locations that were manually cured using BLAST and the nonredundant database of the National Center for Biotechnology Information. 


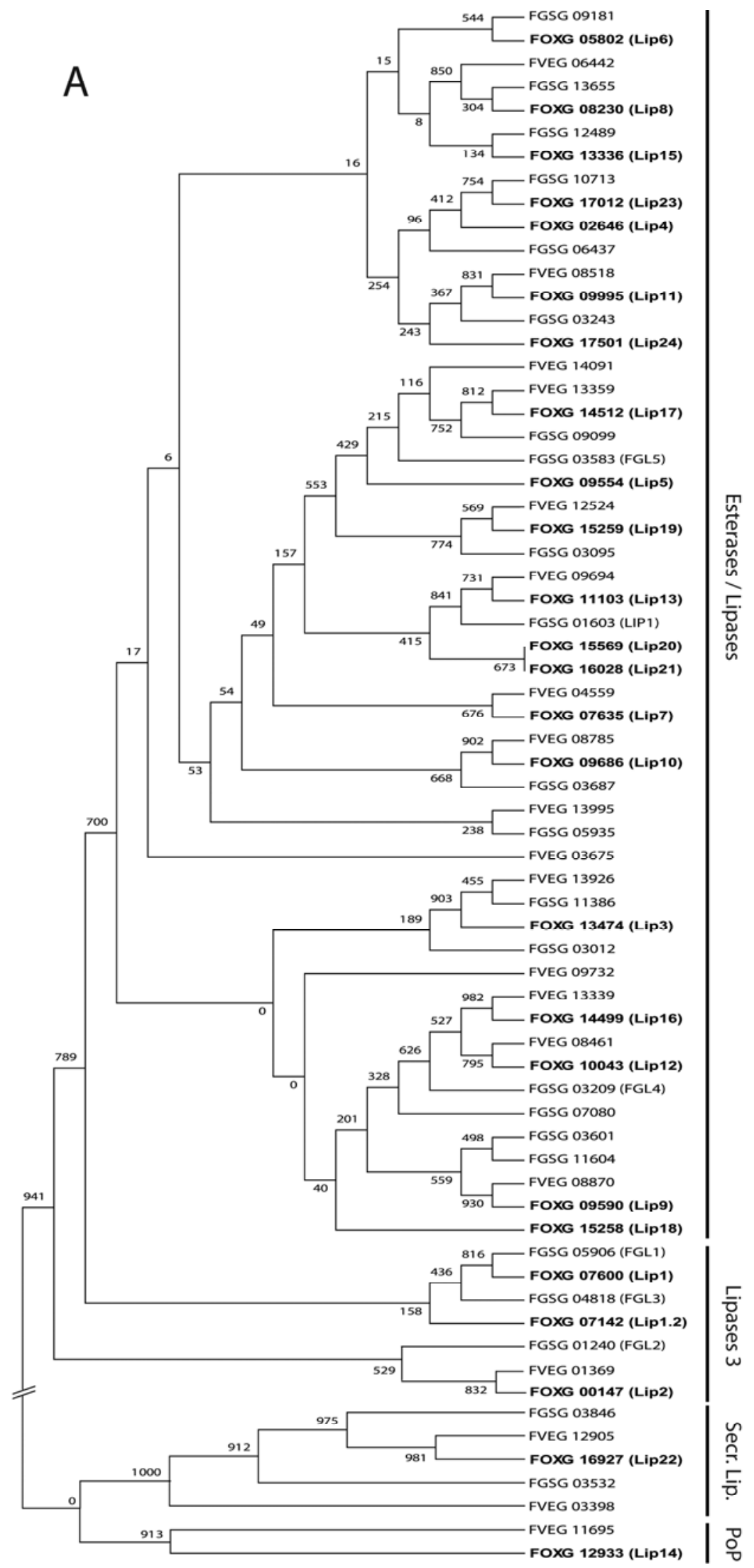

FOXG, Fusarium oxysporum

FGSG, Fusarium graminearum

FVEG, Fusarium verticillioides

Fig. 1. Phylogenetic relationships among Fusarium structural lipases. A, The PHYML 3.0 program (Guindon and Gascuel 2003) was used to perform a 1,000 nonparametric bootstrap phylogenetic analysis of the resulting alignment of 54 amino acid characters with the maximum likelihood method after optimization of the settings by the MODELGENERATOR program, version 0.85 (Keane et al. 2006), depicted in a phylogenetic tree constructed, using MEGA version 4, of structural lipases from $F$. oxysporum with the orthologues from $F$. graminearum and $F$. verticillioides. The 25 structural lipases group within four classes established by the National Center for Biotechnology Information: i) esterases and lipases, ii) lipases class 3, iii) secretory lipases (Secr. Lip.), and iv) prolyl oligopeptidase family (PoP). B, Alignment of conserved regions containing the Gly-X-Ser-X-Gly lipase motif from 25 F. oxysporum structural lipases. Sequence alignment was performed using the ClustalW method with the Bioedit 7.0.0 program (Hall 1999). 
than $\mathrm{e}^{-23}$ for putative $F$. oxysporum protein homologs. The deduced amino acid sequences were obtained from the Broad Institute website and were analyzed. Furthermore, cDNAs of the predicted structural lipase genes lip1, lip2, and lip5 and of the regulatory genes ctfl and ctf 2 were amplified using appropriate primer pairs (Supplementary Table 1) and were sequenced in order to complete or verify, or both, their annotation.

The structural features of lipase genes and their deduced proteins are summarized in Table 1. All the predicted lipases contain the conserved catalytic triad Ser-Asp/Glu-His and the conserved active-site pentapeptide Gly-X-Ser-X-Gly ( $\mathrm{X}$ being any amino-acid) characteristic of fungal lipases (Nardini and Dijkstra 1999). Furthermore, all have a predicted N-terminal signal peptide for secretion.

Sequence alignment of the $F$. oxysporum f. sp. lycopersici predicted lipases with their respective orthologues from $F$. graminearum (Ngygen et al. 2010; Voigt et al. 2005) revealed identities of $77 \%$ for Lip1, 70\% for Lip2, and $68 \%$ for Lip5. Further searches in the comparative genomics database, which provides access to multiple sequenced Fusarium genomes, identified additional lipase orthologues from $F$. graminearun and $F$. verticillioides. The phylogenetic relationship among lipase-encoding sequences from $F$. oxysporum, $F$. graminearum, and $F$. verticillioides was depicted in a phylogenetic tree (Fig. 1A). F. oxysporum structural lipases were grouped within the four classes established by the National Center for Biotechnology Information (NCBI): i) 20 were classified as esterases and lipases (cd00312) (EC.3.1.1.-), ii) three as lipases of class III (cd00519) (EC.3.1.1.3), iii) one as a secretory lipase (cl14925), and iv) one as a prolyl oligopeptidase family (pfam00326). The overall amino acid identities between members of each of the four classes ranged from 15 to $25 \%$, with 50 to $60 \%$ identity in the conserved region containing the pentapeptide GlyX-Ser-X-Gly (Fig.1B). Inspection of the 1,150-bp upstream (promoter) sequences of the $25 \mathrm{~F}$. oxysporum lipase genes revealed that all except lip21 contained between one and eight copies of the palindromic triplet GCC(N)GGC, where $\mathrm{N}$ has a variable length (e.g., 11 in Saccharomyces cerevisiae GAL4) (Liang et al. 1996) reported as recognition motif for $\mathrm{Zn}_{2} \mathrm{Cys}_{6}$ DNA-binding transcription factors (Supplementary Table 2). Additionally, the core DNA element CCGAGG, mediating binding of the transcription factors CTF1 $\alpha$ from $F$. solani $(\mathrm{Li}$ and Kolattukudy 1997; Li et al. 2002) and FarA and FarB from A. nidulans (Hynes et al. 2006) to promoter regions of genes involved in fatty acid metabolism, was found in the promoter region of 12 structural lipase and $c t f l$ genes.

Phylogenetic relationships among the $F$. oxysporum lipase gene regulators $\mathrm{Ctf} 1$ and $\mathrm{Ctf} 2$ as well as orthologues from related fungal species obtained from NCBI were depicted in a phylogenetic tree (Fig. 2A). Ctf1 and Ctf2 group in two different clades that are highly conserved among the different fungal species, including the previously described regulatory proteins FarA and FarB, which control fatty acid catabolism in A. nidulans (Hynes et al. 2006) as well as the cutinase transcription factors Ctf $\alpha$ and Ctf $\beta$ from Nectria haematococca (Li and Kolattukudy 1997; Li et al. 2002). Ctf1 and $\mathrm{Ctf} 2$ as well as their orthologues from A. nidulans and Nectria haematococca contain at least one putative nuclear localization signal and show the $\mathrm{Zn}_{2} \mathrm{Cys}_{6}$ DNA binding domain with the canonical pattern $\mathrm{CX}_{2} \mathrm{CX}_{6} \mathrm{CX}_{7-9} \mathrm{CX}_{2} \mathrm{CX}_{6} \mathrm{C}$ at their amino terminus, characteristic of transcription factors with diverse function (Fig. 2B).

\section{Biochemical characterization of secreted $\boldsymbol{F}$. oxysporum lipases.}

Figure 3A represents an in silico predicted 2-D analysis of the secreted $F$. oxysporum lipases according to the calculated molecular mass and pI (Scansite online calculator). This model predicts two main groups of secreted lipases, one corresponding to proteins with an acidic isoelectric point $(\mathrm{pI})$, including those with the lowest molecular mass, and a second group with basic pI and intermediate molecular mass. 
To experimentally validate the predicted extracellular enzyme profile, concentrated and dialyzed wheat germ oil (WGO)induced culture filtrates of $F$. oxysporum f. sp. lycopersici 4287 were subjected to preparative isoelectric focusing (IEF) at a $\mathrm{pH}$ range of 3 to 10 . Twenty fractions were collected, and lipase activity was determined by the p-nitrophenyl palmitate (pNPP) assay. As shown in Figure 3B, fractions with acidic pI (2.3 to 4.5) contained more than $75 \%$ of the total lipase activity, while fractions with neutral and alkaline $\mathrm{pI}$ values contained less than $15 \%$ of the total activity. The fractions were pooled (1 to 4 [I], 5 to 8 [II], 9 to 12 [III], 13 to 16 [IV], and 17 to 20 [V]), and the resulting pools were analyzed by sodium dodecyl sulfate-polyacrylamide gel electrophoresis (SDS-PAGE) (Fig. 3C). The majority of lower molecular mass proteins were included in fractions I and II, whereas the higher molecular mass proteins appeared at the pI ranging from 6 to 12, supporting the predicted in silico analysis. Nonetheless, the observed protein bands with low pI showed a migration pattern below the expected sizes, which could be due to secretion of nonlipolytic proteins, to posttranslational processing of some lipases, or both. The identity of most of the proteins in fractions II to $\mathrm{V}$ is unknown, since lipase activity in these fractions was very low.

\section{Lipase gene expression during plant infection.}

To investigate the possible role of the predicted lipases in disease progression, quantitative reverse transcription-polymerase chain reaction (qRT-PCR) with gene-specific primers was used to measure the abundance of specific transcripts in roots and stems of tomato plants at different time points after inoculation with the $F$. oxysporum f. sp. lycopersici wild-type strain. Transcription of the $F$. oxysporum actin gene (act) was detected in roots and stems after inoculation and was used for normalization. The transcript pattern of 13 structural genes, lip1, lip1.2, lip2, lip3, lip4, lip5, lip10, lip11, lip13, lip15, lip20, lip21, and lip22, exhibited expression levels varying along a 100-fold range, with lip1, lip3, and lip22 showing the highest induction (20\% relative to actin gene) in roots between 21 and $96 \mathrm{~h}$ after inoculation (Fig. 4). A second group, including lip1.2, lip2, lip10, lip13, and lip21, showed lower expression levels $(0.5 \%$ relative to actin gene), while no transcripts were detected in the remaining genes (data not shown).

\section{Deletion of selected $\boldsymbol{F}$. oxysporum lipase genes.}

To determine whether secreted lipases are required for pathogenicity of $F$. oxysporum f. sp. lycopersici, we performed targeted deletion of the five predicted structural lipase genes lipl, lip2, lip3, lip5, and lip22 and of the predicted lipase regulatory genes ctfl and ctf2. Hygromycin-resistant ( $\mathrm{Hyg}^{\mathrm{R}}$ ) transformants were analyzed by PCR and Southern blot. In all cases, the hybridizing bands of the wild-type strain were replaced by distinct banding patterns with the $\mathrm{Hyg}^{\mathrm{R}}$ cassette in the resulting transformants that had undergone deletion of the lipase genes (Supplementary Figs. 1 to 7 ). To generate a $\Delta c t f 1 \Delta c t f 2$ double mutant, targeted deletion of ctfl was carried out in a $\Delta c t f 2 \mathrm{mu}-$ tant background with the split marker method using the phleomycin resistance $\left(\mathrm{Phl}^{\mathrm{R}}\right)$ cassette as selective marker. In the resulting transformants, the $9.0-\mathrm{kb}$ band containing the open reading frame (ORF) was replaced by a smaller fragment hybridizing with the $\mathrm{Phl}^{\mathrm{R}}$ cassette in transformant number 9 (Supplementary Fig. 8).

RT-PCR experiments were carried out in some cases to confirm successful gene deletion. A 200-bp amplification bandcorresponding to $c t f 1$ or $c t f 2$ transcript was detected in the wild-type strain but was absent in $\Delta c t f 1, \Delta c t f 2$ or $\Delta c t f 1 \Delta c t f 2$ mutants (Supplementary Fig. 9).

Complementation of $\Delta c t f 1$ and $\Delta c t f 2$ mutants was done by cotransformation with DNA fragments containing the $c t f l$ and ctf 2 wild-type alleles, respectively, and the $\mathrm{Phl}^{\mathrm{R}}$ cassette. For $\Delta c t f 1:: c t f 1$ complemented strain, the $1.3-\mathrm{kb}$ band containing the ORF of $c t f l$ was present in transformants 20 and 32 (Supplementary Fig. 10), while for the $\Delta c t f 2:: c t f 2$ complemented strain, the $1.6-\mathrm{kb}$ band containing the ORF of $c t f 2$ was present in transformants 7, 15, and 18 (Supplementary Fig. 11).

\section{Detection of lipase activity in the wild-type and mutant strains.}

In order to determine the effect of gene deletions on secreted lipolytic enzyme production, we measured total specific activity in 18 to $20 \mathrm{~h}$ WGO-induced culture supernatants from the different strains (Fig. 5). Among the lipase gene mutants, $\Delta$ lipl showed the strongest decrease in activity measured by the pNPP assay ( $80 \%$ relative to wild type), while $\Delta$ lip 2 and $\Delta$ lip 5 retained almost $90 \%$ of the wild-type activity, and lip3 and lip22 showed similar levels as the wild-type strain. Mutants lacking regulatory lipase genes showed a significant (10 to $30 \%$ ) reduction in comparison with the wild-type strain. Reintroduction of the corresponding wild-type allele into the $\Delta c t f 1$ or $\Delta c t f 2$ mutant strains restored wild-type lipase activity levels.

A reddish color was present in the lipidic fraction of WGOinduced culture supernatants from all fungal strains except $\Delta$ lip1, $\Delta c t f 1$, and $\Delta c t f 1 \Delta c t f 2$ mutants (Fig. 6A). The absorbance of these fractions at different wavelengths (200 to 600 $\mathrm{nm}$ ) revealed a peak at $510 \mathrm{~nm}$ in the reddish samples that was absent in the yellowish fractions (Fig. 6B). To further characterize the chemical nature of the pigments, the compounds were isolated from culture supernatants of wild-type and mutant strains and were analyzed by preparative high-performance liquid chromatography (HPLC) and mass spectrometry (MS). This analysis determined that the red pigment corresponded to a compound of molecular weight 383 . F. oxysporum is known to produce the noncarotenoid red pigment bikaverin (Son et al. 2008). Using this compound as standard, we determined bikaverin to be solely responsible for the reddish coloration of the lipidic fraction of WGO-induced cultures from wild type, $\Delta$ lip2, $\Delta$ lip3, $\Delta$ lip5, $\Delta$ lip22, $\Delta$ ctf2, $\Delta$ ctf1::ctf1, and $\Delta c t f 2:: c t f 2$, thus demonstrating that $\Delta$ lip $1, \Delta c t f 1$, and $\Delta c t f 1 \Delta c t f 2$ mutant strains produced no detectable bikaverin under this condition (Fig. 6C).

To further investigate the effect of the deletion of regulatory and structural lipase-encoding genes on the ability to metabolize different fatty acids, we analyzed colonial growth of the wild type and the mutants on solid media containing longchain or short-chain fatty acids, olive oil, and WGO as the sole carbon source. No significant differences were observed in the growth of any structural lipase mutant in comparison with the wild-type strain (data not shown). By contrast, $\Delta c t f 1, \Delta c t f 2$, and $\Delta c t f 1 \Delta c t f 2$ mutants showed growth defects in the presence of fatty acids (Fig. 7). $\Delta c t f 1$ mutant produced mycelia with fewer aerial hyphae in the presence of long-chain fatty acids as sole carbon source, while deletion of ctf 2 severely impaired growth in short-chain (sodium acetate, sodium butyrate, gly3butyrate, or erucic acid) and moderately in long-chain (sodium oleate, gly3oleate, gly3palmitate, olive oil, or WGO) fatty acids, with an additive phenotypic defect in the double mutant.

\section{Expression of lipase genes}

in F. oxysporum f. sp. lycopersici mutants.

The induction of microbial lipase production by lipids in the growth medium has been reported (Novotnyy and Dolezalová 1993). To investigate regulation of lip1, lip1.2, lip2, lip3, lip4, lip5, lip10, lip11, lip13, lip15, lip20, lip21, and lip22 gene expression, quantitative RT-PCR analyses were performed using RNA extracted from mycelia of $F$. oxysporum cultures $20 \mathrm{~h}$ after induction in synthetic medium (SM) supplemented with $2 \%$ 


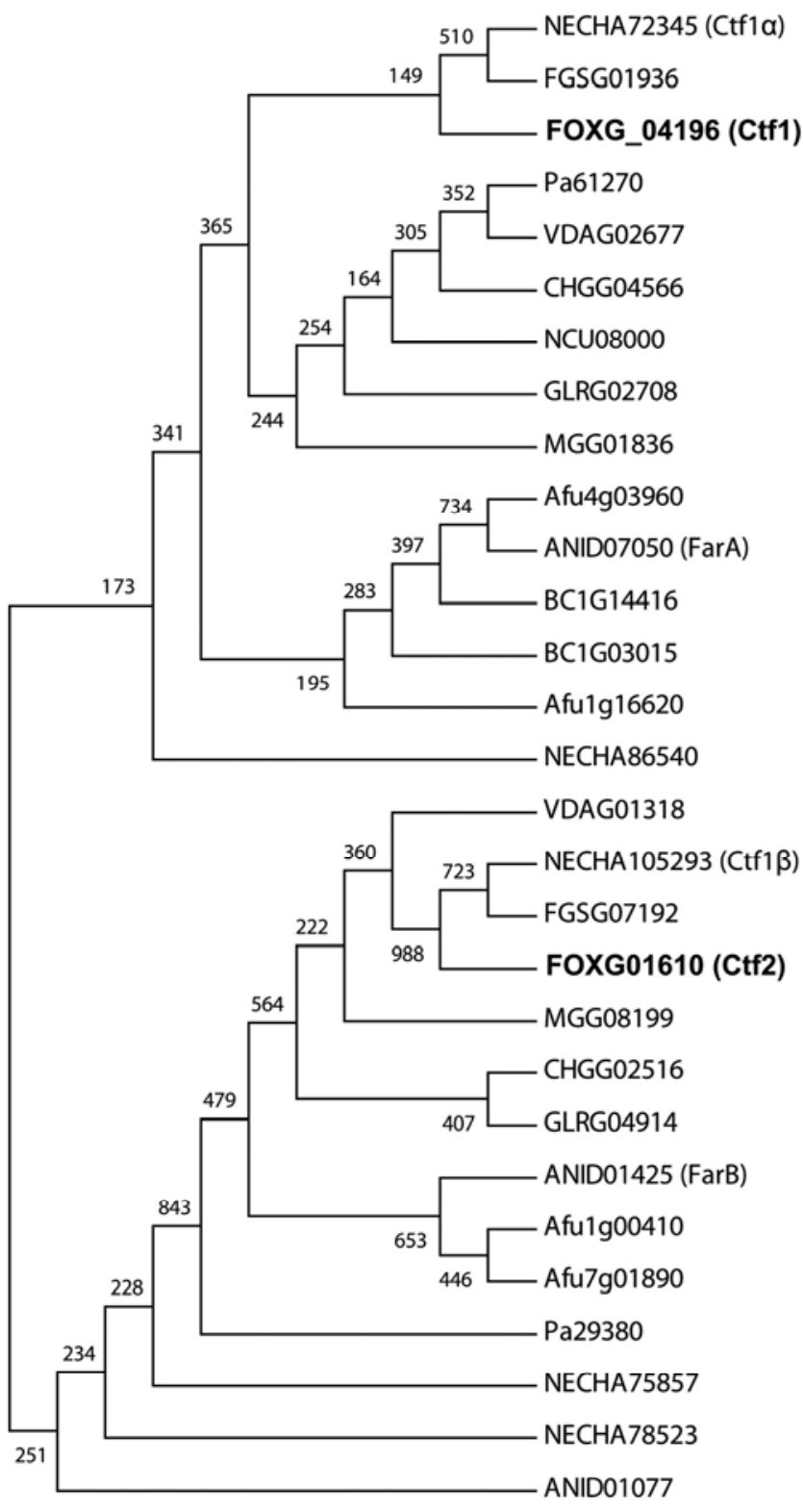

FOXG, Fusarium oxysporum

FGSG, Fusarium graminearum

$\mathrm{NECHA}$, Nectria haematococca

$\mathrm{Pa}$, Podospora anserina

f VDAG, Verticillium dahliae

CHGG, Chaetomium globosum

NCU, Neurospora crassa

GLRG, Glomerella graminicola

MGG, Magnaporthe oryzae

Afu, Aspergillus fumigatus

ANID, Aspergillus nidulans

BC1G, Botryotinia fuckeliana

B

NLS

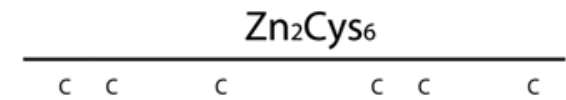

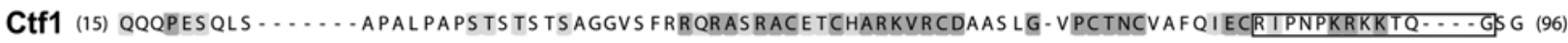
Ctf1 $\alpha$ (16) QEQPNQRQSS TPAPS AAPVPPAPSTS TS NS AGGVS FRRQRASRACE TCHARKVRCDAAS LG - VPCTNCVAFQIECRIPNPKRKKTQ- - - GTG (104) FarA (16) PSPTPSTAG ........ STGTAGISVRAGANGQMS FRRQRASRACETCHARKVRCDAAS LG - VPCTNCVAFS IECRIPTPKRKKSQAKPREVG (100) Ctf2 (16) ATSVKASNE -......... KNSKKRAS PSGDSEQPEK I TKRRAARACVSCRARKVRCDVVEG - APCGNCRWDNVECVVQESRRRKKNLYTASTA (99) Ctf1 $\beta$ (16) STSAKTVTD-......... KTNKKRAS PSGDSEQPTKVTKRRAARACVSCRARKVRCDVVEG - APCGNCRWDNVECVVQESRRRKKNLLTAS TA (99) FarB (12) ET DPKSKRK ……............ ASSAGLSANSRPVKRRASKACCCCRARKVRCDVVENG - S PCTNCRLDQVECVVTESKRRKKSRVDTEIS (89) NECHA_78523 (1) - - MPLSNDR ........................ PHRRAHVACKACNARKARCTVTLS G. PPCANCAVDNVLCE

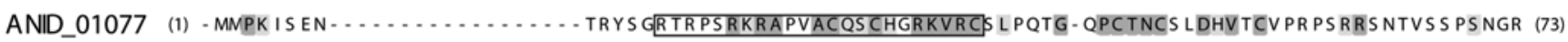
NECHA_75857 (2) ESNQQQQQD .................... YQDLPRRRQQRKACDVCRRRKVRCDIVLRPEGPCSVGEKS GLECRS TAKWATPRRGS TAPRR (72) NECHA_86540 (11) PTSFTKKRK.......... PNTFVSAEHTFV I DNQASKGRERPGVVHASS TNRPCVVELPCFG... CHLSAYSNLGFFRENV I DHAFEVLPHS GE (92)

Fig. 2. Phylogenetic relationships among fungal lipase gene regulators. A, The PHYML 3.0 program (Guindon and Gascuel 2003) was used to perform a 1,000 nonparametric bootstrap phylogenetic analysis of the resulting alignment of 54amino acid characters with the maximum likelihood method after optimization of the settings by the MODELGENERATOR program, version 0.85 (Keane et al. 2006), depicted in a phylogenetic tree constructed, using MEGA version 4, of Ctf1 and Ctf2 lipase regulators of Fusarium oxysporum and the orthologues in closer fungal species. B, Alignment includes amino acid sequences from predicted $\mathrm{Zn}_{2} \mathrm{Cys}_{6}$ zinc finger regions of several fungal lipase gene regulators. Putative nuclear localization signals (NLS) and the $\mathrm{Zn}_{2} \mathrm{Cys}{ }_{6}$ DNA-binding domain are indicated. Sequence alignment was performed using the ClustalW method with the Bioedit 7.0.0 program. 
( vol/vol) $\mathrm{WGO}$ at $28^{\circ} \mathrm{C}$ (Fig. 8). Deletion of ctfl or ctf 2 affected the expression of most structural lipase genes analyzed. Positive regulation by both factors was found for seven genes, lip1, lip2, lip3, lip10, lip13, lip15, and lip22. Additionally, Ctf1 showed negative regulation on genes lip1.2, lip20, and lip21, whereas transcription factor Ctf2 negatively affected expression of lip1.2. The double mutant showed an additive phenotypic effect on the regulated genes. No expression of lip4 and lip5 was detected in any of the strains under the conditions tested (data not shown). No significant differences were detected between wild type and the complemented strains $\Delta c t f 1:: c t f l$ and $\Delta c t f 2:: c t f 2$.

Virulence of lipase deficient transformants on tomato plants.

The role of lipases in virulence of $F$. oxysporum f. sp. lycopersici was determined by pathogenicity tests performed by immersing the roots of 2 -week-old tomato plants in microconidial suspensions of the wild-type strain, the $\Delta$ lip1, $\Delta$ lip2,
A

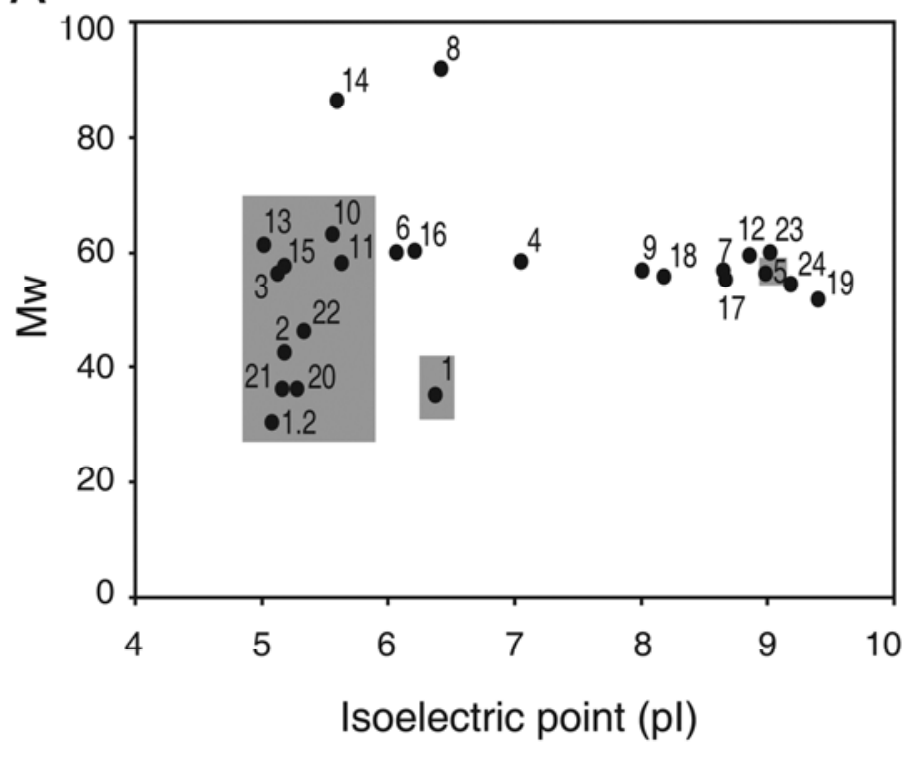

\begin{tabular}{l|l|ll|l|l|l}
$\begin{array}{l}\text { Deduced } \\
\text { protein }\end{array}$ & MW (kDa) & pl & \multicolumn{2}{c|}{$\begin{array}{l}\text { Deduced } \\
\text { protein }\end{array}$} & MW (kDa) & pl \\
\hline Lip13 & 61,16 & 5,02 & Lip1 & 35,03 & 6,38 \\
Lip1.2 & 30,47 & 5,08 & Lip8 & 91,93 & 6,42 \\
Lip3 & 56,11 & 5,13 & Lip4 & 58,34 & 7,05 \\
Lip21 & 36,15 & 5,17 & Lip9 & 56,65 & 8,01 \\
Lip2 & 42,44 & 5,18 & Lip18 & 55,67 & 8,18 \\
Lip15 & 57,40 & 5,18 & Lip7 & 56,80 & 8,65 \\
Lip20 & 36,08 & 5,28 & Lip17 & 55,18 & 8,67 \\
Lip22 & 46,11 & 5,34 & Lip12 & 59,38 & 8,86 \\
Lip10 & 63,16 & 5,56 & Lip5 & 56,14 & 8,99 \\
Lip14 & 86,33 & 5,60 & Lip23 & 60,01 & 9,02 \\
Lip11 & 58,16 & 5,64 & Lip24 & 54,35 & 9,19 \\
Lip6 & 59,81 & 6,07 & Lip19 & 51,80 & 9,40 \\
Lip16 & 60,28 & 6,21 & & &
\end{tabular}

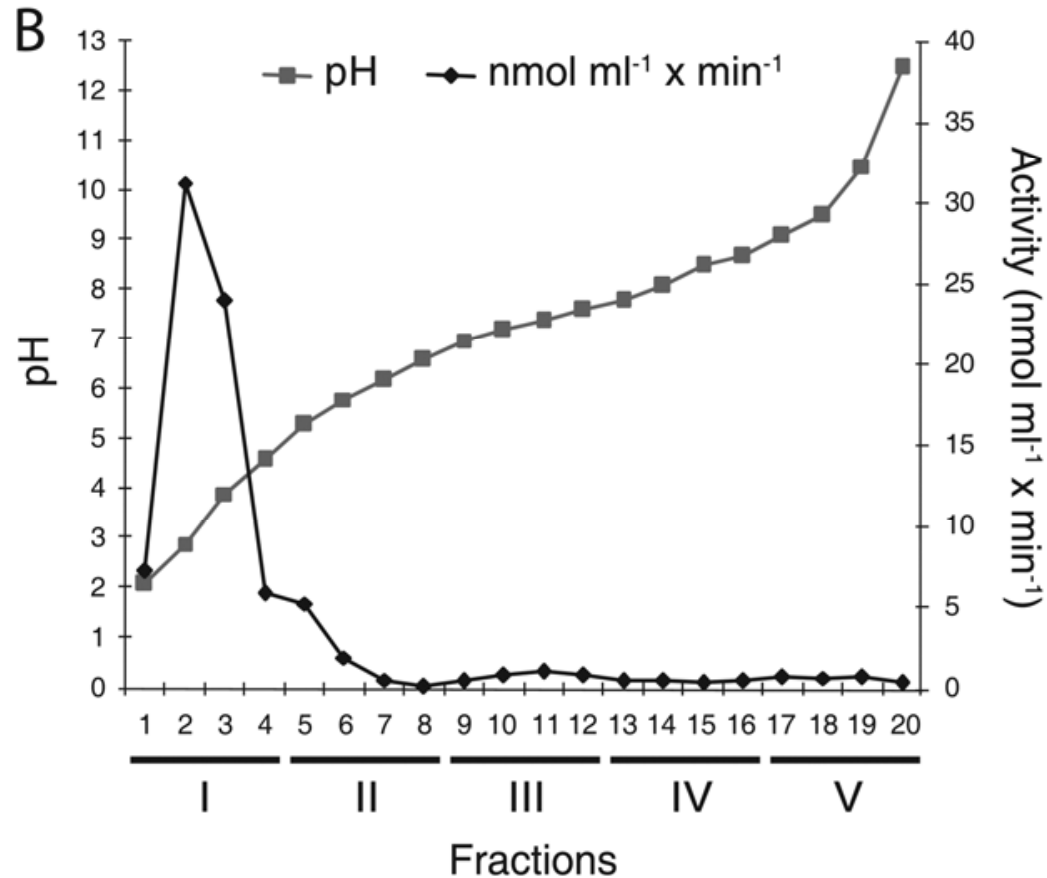

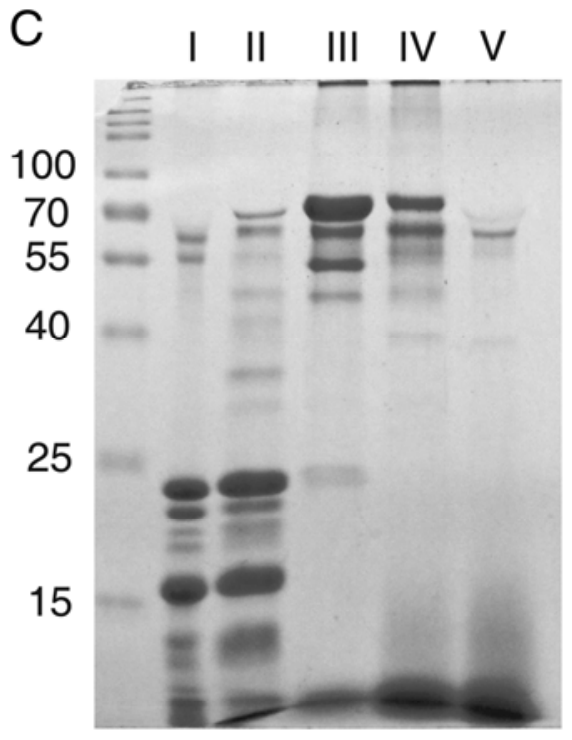

Fig. 3. Biochemical analysis of the Fusarium oxysporum f. sp. lycopersici extracellular lipase profile. A, Two-dimensional representation of predicted secreted lipases, theoretical molecular mass $(\mathrm{Mw})$ and isoelectric points ( $\mathrm{pI}$ ) from deduced amino acids of the corresponding genes obtained by in silico analyses at the Scansite website. Lipases with low pI as well as Lip1 and Lip5 are shaded. B, Biochemical validation by preparative isoelectric-focusing (pH 3 to 10) on a Rotofor apparatus of concentrated and dialyzed culture filtrates from $F$. oxysporum f. sp. lycopersici wild-type strain grown on synthetic medium supplemented with $2 \%$ wheat germ oil. Twenty fractions were collected after the run, and the lipase activity profile was determined by the p-nitrophenyl palmitate assay. C, Fractions were pooled together in five different groups (I to V) after enzymatic activity determination, and the proteins present in the pools were analyzed by sodium dodecyl sulfate-polyacrylamide gel electrophoresis. Numbers indicate molecular mass in kiloDaltons. 
Llip3, $\Delta$ lip5, $\Delta$ lip22, $\Delta c t f 1, \Delta c t f 2$, and double $\Delta c t f 1 \Delta c t f 2 \mathrm{mu}-$ tants, their complemented strains, and the corresponding ectopic transformants for all disrupted genes. Plant survival was recorded daily for 35 days, as previously described (Fig. 9). Most plants inoculated with the wild-type strain or the ectopic transformants (not shown) were dead 20 days after inoculation. By contrast, mortality of plants inoculated with the $\Delta c t f 2$ and the $\Delta c t f 1 \Delta c t f 2$ mutants was significantly reduced $(P<$ 0.0001 ), with $80 \%$ of the plants still alive after 25 days, whereas plants inoculated with $\Delta c t f 1$ mutant showed a $40 \%$ survival rate $(P<0.0005)$. The apparent discrepancy between the previous $\Delta c t f 1$ mutant (Martínez Rocha et al. 2008) showing attenuated virulence on tomato plants (cv. Vemar) and those included in the present manuscript (cv. Moneymaker) could be due to the different genetic backgrounds of these cultivars. Complementation of $\Delta c t f 1$ and $\Delta c t f 2$ mutants with the corresponding wild-type allele completely restored pathogenicity. The remaining mutants did not show differences in virulence compared with wild type (data not shown).

\section{DISCUSSION}

While a role of lipolytic enzymes during infection of aerial plant pathogens has been established (Feng et al. 2005; Paper et al. 2007; Voigt et al. 2005), the function of these enzymes has not been investigated in soilborne fungal pathogens. To test the role of lipid-degrading enzymes in virulence of the soilborne vascular wilt pathogen $F$. oxysporum, we performed a genetic and biochemical characterization of the lipolytic system of this fungus, including targeted deletion of a number of secreted lipase and lipase regulatory genes.

Genome searches revealed the presence of a higher number of predicted secreted lipase genes in the $F$. oxysporum genome compared with the closely related species $F$. graminearum and $F$. verticillioides, as previously reported for this species complex (Ma et al. 2010). The differences in the number of lipase genes in the three Fusarium species may point to divergent evolutionary mechanisms during adaptation of the infection process in root and aerial plant pathogens. In root pathogens, the apparent redundancy in lipolytic enzymes may have evolved from a common ancestor by gene duplication leading to a better adaptation for the specific requirements encountered during host penetration. Similar differences have been reported for cutinase genes in $F$. oxysporum, which contains a single cutinase gene (Martínez-Rocha et al. 2008), as opposed to three in F. solani (Li et al. 2002). In this work, 24 predicted lipases phylogenetically related to Lip1 (Martinez-Rocha et al.
2008) were identified. They all contain a putative lipase domain of five amino acid peptide (pentapeptide) Gly-X-Ser-XGly, as found in FGL1 to FGL5 and LIP1 in F. graminearum (Feng et al. 2005; Nguyen et al. 2010; Voigt et al. 2005). This domain is known as the central active site, in which serine functions as a catalytic residue (Blow 1992; Lowe 1992; Shen et al. 1998). Also, a putative secretion sequence is present at the N-terminus of each lipase. Although lipases share several common features, such as structural fold and identical catalytic machinery, they appear to be variable in amino acid sequence (Fischer and Pleiss 2003). Phylogenetic analysis of the 25 deduced amino acid sequences of $F$. oxysporum revealed four major clades of lipases, including esterases and lipases, lipases class III, secretory lipases, and a prolyl oligopeptidase, which have different substrate specificity (Fig. 1). Lipases (EC 3.1.1.3.) and esterases (EC 3.1.1.1.) both catalyze the hydrolysis of carboxyl ester bonds. For many years, the distinction between esterases and lipases has been based on their substrate specificity and their capacity to hydrolyze esters in solution or emulsion, respectively. It is generally considered that lipases hydrolyze water-insoluble, medium- and long-chain triacylglycerols such as trioctanoin and triolein, although they also display high activity against somewhat (slightly) water-soluble emulsions, whereas esterases act on solutions of short-chain, fatty acyl esters such as methyl butyrate, ethyl butyrate, and

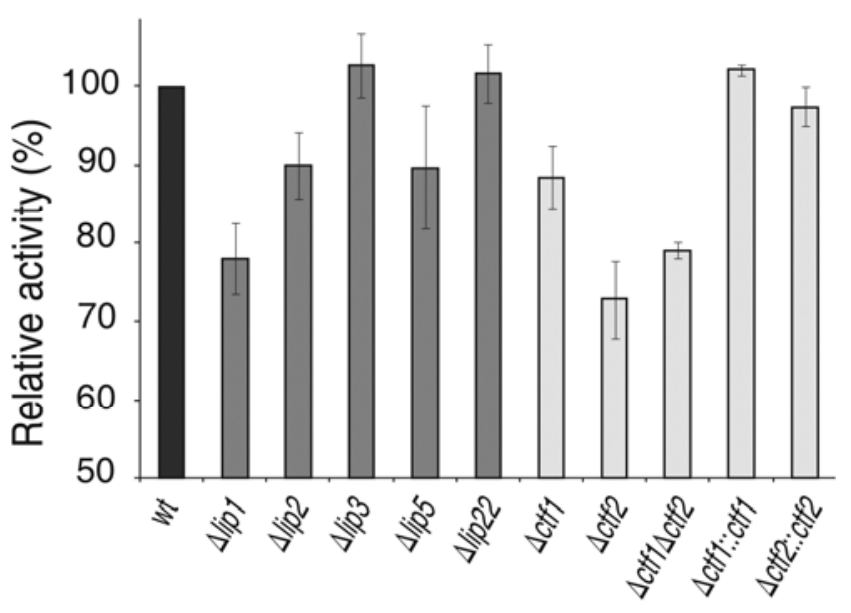

Fig. 5. Lipolytic activity from Furasrium oxysporum strains. Lipase activity in wheat germ oil-induced cultures is represented relative to that observed in the wild-type strain (wt). Bars represent standard errors calculated from three biological replicates, each including three technical replicates.
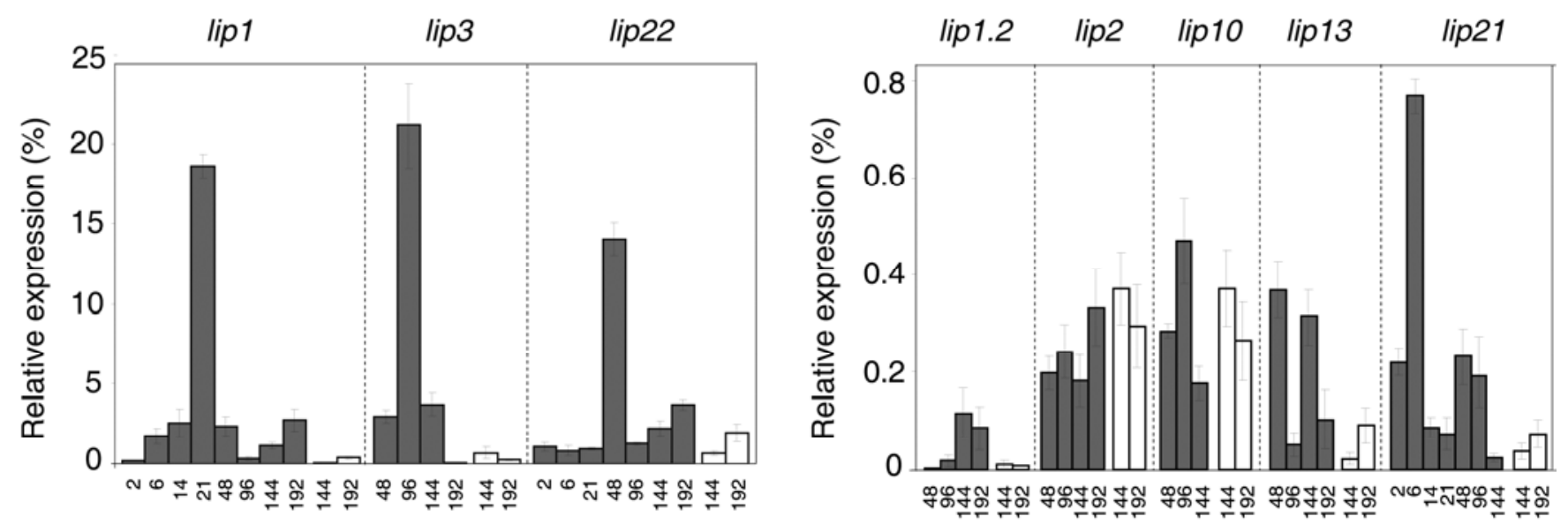

Fig. 4. Analysis of gene expression by quantitative reverse transcription-polymerase chain reaction during tomato pathogenicity tests with Fusarium oxysporum f. sp. lycopersici. Samples for RNA isolation from infected roots (black bars) or stems (white bars) were taken at the indicated time periods, from 2 to $192 \mathrm{~h}$ after tomato plant inoculation. Bars represent standard errors calculated from three biological replicates, each including three technical replicates. 


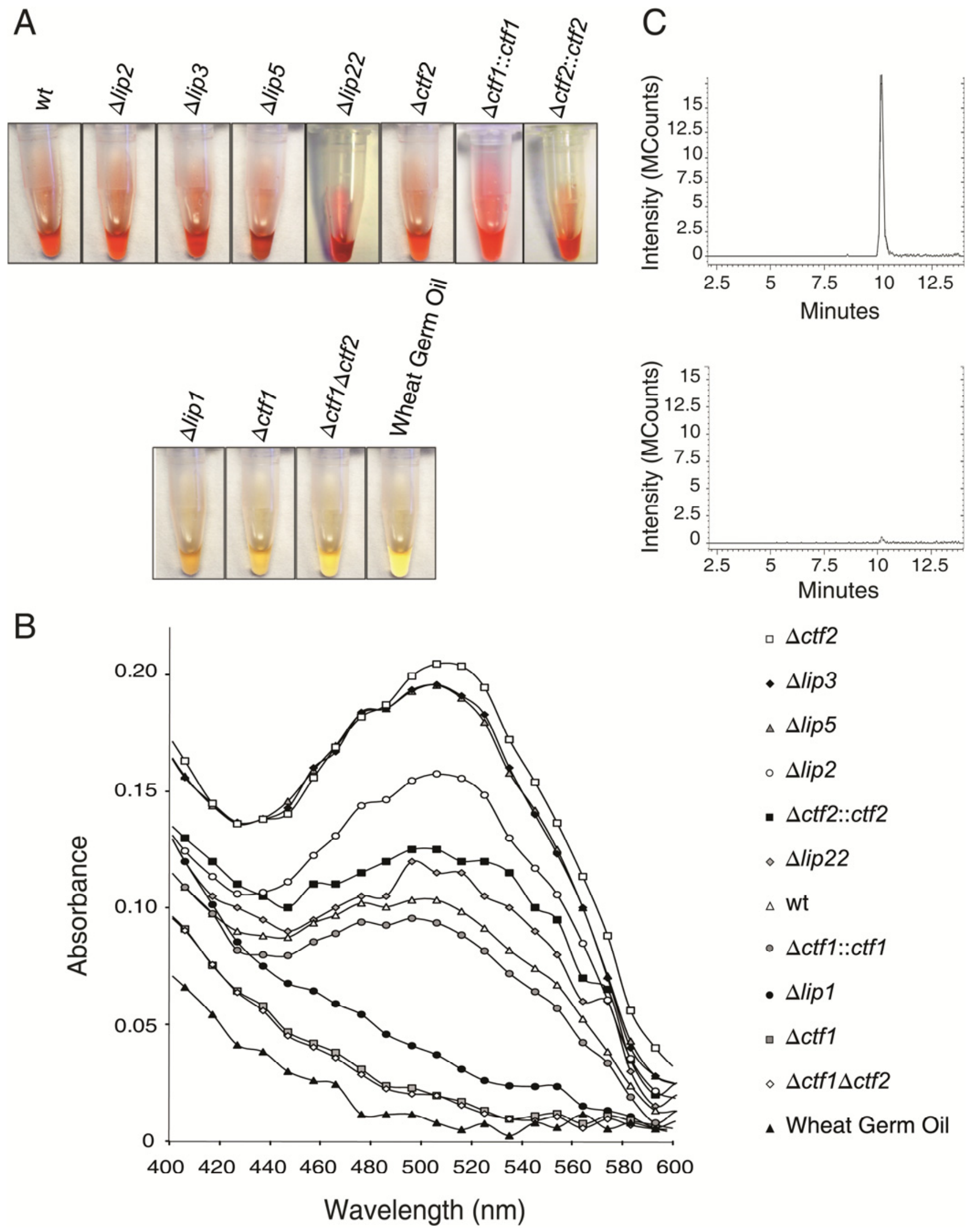

Fig. 6. Analysis of pigments produced by Fusarium oxysporum strains. A, Photographs showing the color of the lipidic fraction of wheat germ oil-induced culture supernatants from the wild-type strain (wt) and the indicated mutants. B, Absorbance of the lipidic fraction from each strain was determined at wavelengths from 400 to $600 \mathrm{~nm}$. C, High-performance liquid chromatography (HPLC)-ionic chromatograms obtained from the wild type (upper panel) and the $\Delta c t f 1$ mutant (lower panel) using bikaverin as standard. Retention time from which the sample is injected into the HPLC is represented. Chromatograms from the remaining strains were similar either to the wild type or the $\Delta c t f 1$ mutant. 
triacetin, which are poorly hydrolyzed by lipases (Chahinian et al. 2002). Besides their important role in biotechnology, lipases are potential virulence factors for pathogenic bacteria and fungi. On the other hand, secretory lipases are thought to be produced during the infection cycle of pathogenic species. In particular, Candida albicans produces a large number of different lipases that may contribute to its persistence and virulence in human tissues (Hube et al. 2000). The existence of this broad lipolytic profile in F. oxysporum $\mathrm{f}$. sp. lycopersici could reflect their diverse roles during nutrient acquisition or infection of the host plant.

Besides the previously described $F$. oxysporum ctfl gene (Martínez-Rocha et al. 2008), we identified a second gene, $\operatorname{ctf} 2$, encoding a putative regulator of lipase activity with homology to transcription factors regulating fatty acid metabolism in A. nidulans (FarB) (Hynes et al. 2006) or cutinolytic activity in $F$. solani (Ctf $\beta$ ) (Li and Kolattukudy 1997; Li et al. 2002) (Fig. 2). The two predicted $F$. oxysporum lipase regulatory proteins contain at least one putative nuclear localization signal, and their amino termini show the $\mathrm{Zn}_{2}$ (II)Cys ${ }_{6}$ DNAbinding domain, characteristic of regulatory proteins with diverse function. This group of transcription factors binds to promoter regions at two conserved palindromic triplets GCC $(\mathrm{N})_{\mathrm{x}} \mathrm{GGC}$, where $\mathrm{N}$ has a variable length (e.g., 11 in Saccharomyces cerevisiae GAL4) (Liang et al. 1996). In F. solani f. sp. pisi, the DNA motifs recognized by $\mathrm{Ctf} \alpha$ have the opposite orientation and are separated only by two nucleotides (GCCN ${ }_{2}$ GGC) (Li et al. 2002), while in A. nidulans FarA and FarB bind to the conserved motif CCGAGG in the promoter region of the target genes (Hynes et al. 2006). We previously noted that the promoter of the $F$. oxysporum ctfl gene contains a copy of the CCGAGG motif, suggesting that Ctf1 may regulate its own expression (Martinez-Rocha et al. 2008). Furthermore, the promoter regions of 24 identified lipase genes in $F$. oxysporum contain copies of the $\mathrm{CGGN}_{\mathrm{n}} \mathrm{CCG}$, similar to the DNA motif recognized by $F$. solani $\mathrm{CTF} \alpha$, besides the CCGAGG DNA element located in the promoter regions of lip1 (Martinez-Rocha et al. 2008) as well as of 12 additional structural lipases. Taken together, these results suggest the existence of a complex lipolytic system in $F$. oxysporum.

Our results demonstrate that lipolytic activity in supernatants of $F$. oxysporum cultures is inducible by lipid substrates such as WGO, leading to the secretion of a battery of lipase enzymes with different physical and chemical profiles (Fig. 3). As a first approach to investigate the role of the predicted lipases in disease progression of $F$. oxysporum $\mathrm{f}$. sp. lycopersici, qRT-PCR with gene-specific primers was used to detect the presence of specific transcripts in roots and stems of tomato plants at different time points after inoculation with wildtype strain (Fig. 4). We observed three different patterns among the tested genes. One group comprises genes that are highly induced during plant infection, including lip1, lip3, and lip22 as the highest expressed; a second group includes genes with low expression levels; the remaining genes corresponded to lipases whose transcripts were not detected during plant infection. The secreted lipase genes showed maximum expression at different time points, suggesting that they may function at different stages during plant infection. These results show that transcripts of most analyzed lipase genes are detectable in planta, indicating the inductivity of the endogenous promoters regulating secreted lipases, and suggest that the diverse secreted lipases may play different roles during nutrient acquisition or colonization of tomato plants.

To further determine whether lipases are necessary for pathogenicity of $F$. oxysporum f. sp. lycopersici, we performed targeted deletion of five predicted structural lipase genes lip1, lip2, lip3, lip5, and lip22, and two predicted lipase regulatory genes, ctfl and $c t f 2$. A disrupted ctfl loss-of-function allele was previously constructed in our laboratory (Martínez-Rocha et al. 2008), and complete gene deletion in the present study produced similar phenotypes. Deletion of most secreted lipase, particularly in the lipase regulatory genes, resulted in a significant reduction of total lipase activity (between 10 to $30 \%$ compared with the wild-type strain), showing an additive effect in the $\Delta c t f 1 \Delta c t f 2$ double mutant (Fig. 5). These results suggest that the regulatory genes identified in $F$. oxysporum are required for expression of genes involved in fatty acid hydrolysis and that deletion of a single secreted lipase can also affect total activity.

The visual detection of red pigment accumulation, identified as bikaverin, in the lipidic fraction of WGO-induced culture supernatants indicated significant differences in $\Delta$ lipl, $\Delta c t f 1$, and $\Delta c t f 1 \Delta c t f 2$ mutant phenotypes compared with the wildtype strain (Fig. 6). These results are consistent with the hypothesis that Lip1 is actively involved in WGO metabolism, producing intermediates that are essential for bikaverin biosynthesis, and that this pathway is partially regulated by $\mathrm{Ctf} 1$. Bikaverin biosynthesis, a frequent trait in Fusarium spp. but rarely found in other fungi, involves six clustered genes showing conserved synteny between species (Limón et al. 2010). An increase in expression of the bikaverin biosynthesis genes and, thus, of bikaverin production has been recently reported in the Fusarium fujikuroi $\Delta$ Ffvell mutant. The complexity of

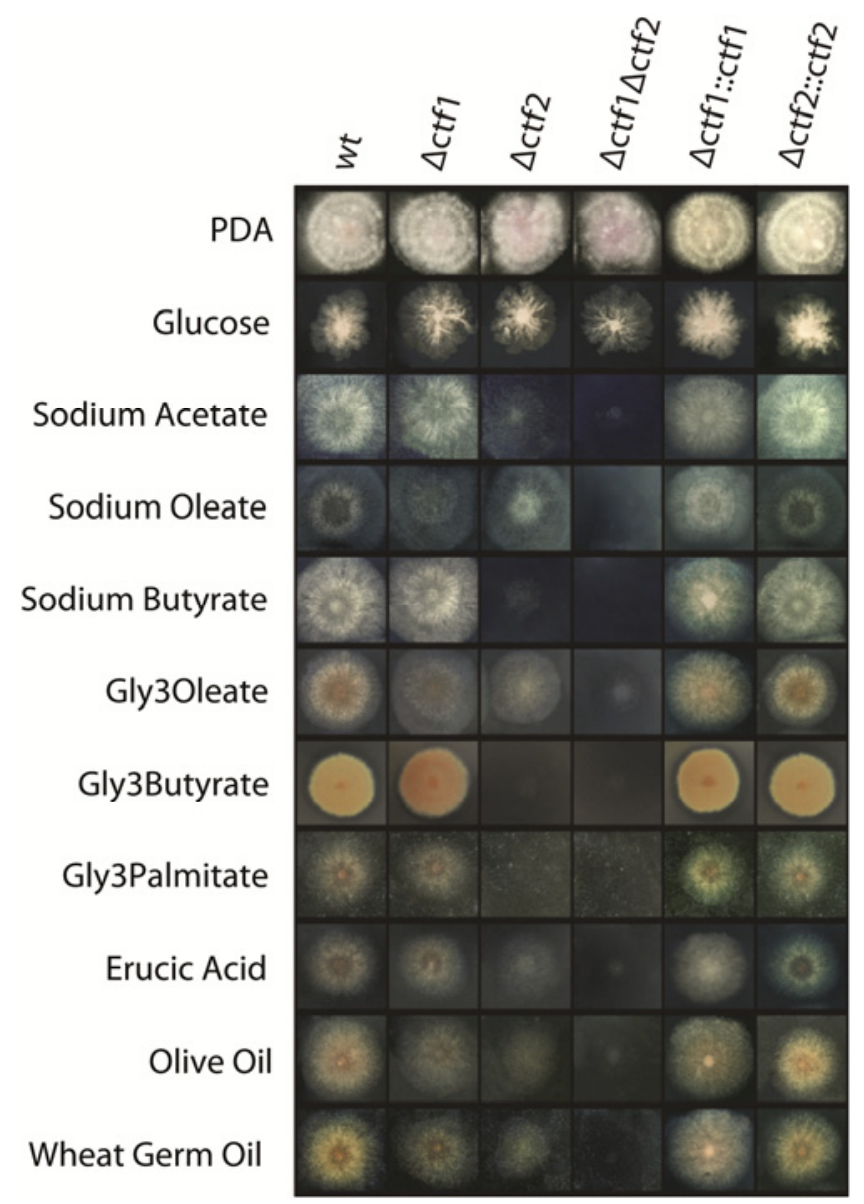

Fig. 7. Fungal colonies of the wild type (wt) and the indicated mutant strains were grown for 6 days at $28^{\circ} \mathrm{C}$ on synthetic media (SM) containing the indicated fatty acid as the sole carbon source in the following amounts: $50 \mathrm{mM}$ sodium acetate, $2.5 \mathrm{mM}$ sodium oleate, $10 \mathrm{mM}$ sodium butyrate, $0.5 \%$ (wt/vol) glycerol tri(3)oleate, $0.5 \%$ (vol/vol) glycerol tri(3)butyrate, $0.5 \%$ (vol/vol) glycerol tri(3)palmitate, $2.5 \mathrm{mM}$ erucic acid, $0.5 \%$ (vol $/ \mathrm{vol})$ olive oil, or $0.5 \%$ (vol/vol) wheat germ oil. Complete medium (PDA [potato dextrose agar]) or SM with $1 \%$ glucose were used as controls. 
the bikaverin regulatory network in response to external signals suggests that de-repression of bikaverin genes is a secondary effect of Ffvell deletion, due to a defective perception of environmental signals (Wiemann et al. 2009 2010).

In our assays, only $\Delta c t f 1, \Delta c t f 2$, and double $\Delta c t f 1 \Delta c t f 2 \mathrm{mu}-$ tants were affected in the ability to metabolize different fatty acids (Fig. 7). By contrast, structural lipase mutants did not show detectable differences compared with the wild-type strain. Deficiency in ctfl slightly affected long-chain fatty acids metabolism, as deduced by the sparse mycelium observed on plates containing these as sole carbon source, whereas deletion of ctf2 severely impaired metabolism of short-chain and, moderately, of long-chain fatty acids, with an additive phenotypic defect in the double mutant strain (Fig. 7). These results contrast with those reported in A. nidulans, in which deletion of the farA gene (orthologue to ctfl) abolished induction of a number of genes by both short- and long-chain fatty acids, while deletion of the $\operatorname{far} B$ gene (orthologue to $c t f 2$ ) eliminated short-chain induction (Hynes et al. 2006). This suggests that similar transcription factors may play different regulatory roles in fatty acid metabolism among different fungal species.

Using qRT-PCR experiments with WGO-induced mycelia of the different strains, we found that $\mathrm{Ctf} 1$ together with $\mathrm{Ctf} 2$ activates transcription of several structural lipase genes, including lip2, lip3, lip10, lip13, lip15, and lip22, in addition to the previously described role as a positive regulator of lip1 (Martínez-Rocha et al. 2008). On the other hand, Ctf1 appears to function as a negative regulator of lip1.2, lip20, and lip21, whereas transcription factor $\mathrm{Ctf} 2$ only had a negative effect on lip1.2. As expected, the double mutant showed an additive phenotypic effect on the regulated genes (Fig. 8). These results demonstrate a complex transcriptional regulation of secreted lipases by both Ctf 1 and Ctf 2 during in vitro growth. We cannot exclude a different regulatory profile for the secreted lipases of $F$. oxysporum during infection of tomato plants, similar to that described for Lip1 during tomato root infection (MartínezRocha et al. 2008).

Our results demonstrate that individual lipase genes are dispensable for fungal virulence (Fig. 9). This contrasts with the severe reduction in virulence resulting from deletion of FGL1 in F. graminearum (Voigt et al. 2005). Previously, it was reported that disruption of $F$. graminearum LIPI led to decreased lipolytic activity in the culture supernatant, indicating that $L I P I$ is a secreted lipase. However, LIP1 was not required for pathogenicity (Feng et al. 2005). Although no evidence for the involvement of individual lipases in virulence of $F$. oxysporum was found, their function in nutrient acquisition may be important. It is likely that secreted lipases are required for lipid utilization, since disruption of the genes caused decreased lipolytic activity of the mutants in comparison with the wild-type strain. Thus, individual lipases may be dispensable due to upregulation of other secreted lipases. This hypothesis is supported by the finding that virulence is reduced in the regulatory mutant $\Delta c t f l$ and severely attenuated in the regulatory mutants $\Delta c t f 2$ and $\Delta c t f 1 \Delta c t f 2$, suggesting that deregulation of a multiple set of lipase genes affects pathogenicity in F. oxysporum.

\section{MATERIALS AND METHODS}

Phylogenetic analysis of lipase genes.

Amino acid sequences were aligned using the CLUSTALW algorithm (Thompson et al. 1994) with the Bioedit 7.0.0 program (Hall 1999) and were cleaned by GBlocks v0.91b (Castresana 2000). The PHYML 3.0 program (Guindon and Gascuel 2003) was used to perform a 1,000 nonparametric

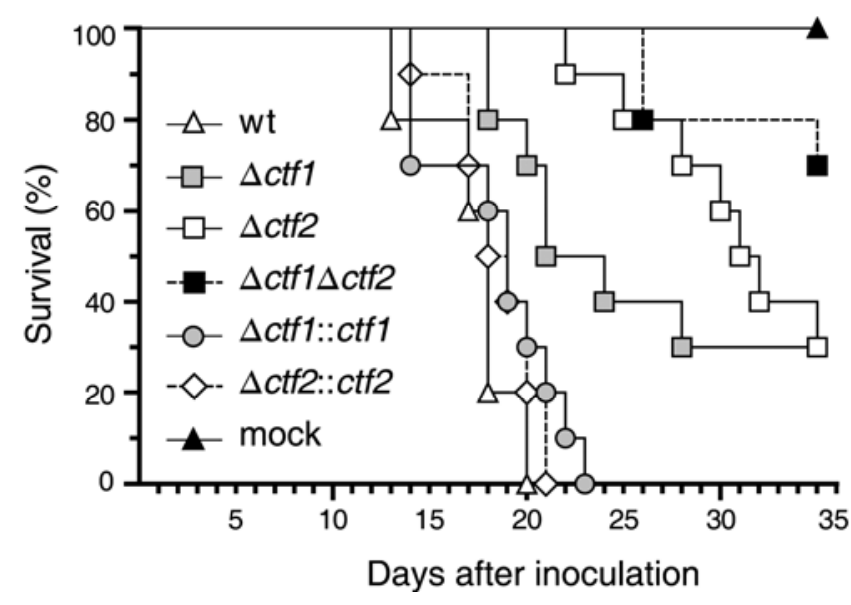

Fig. 9. Incidence of Fusarium wilt of tomato plants (cv. Moneymaker) caused by the wild-type strain (wt), lipase regulatory mutants $\Delta c t f 1, \Delta c t f 2$, and $\Delta c t f 1 \Delta c t f 2$, and the complemented strains $\Delta c t f 1:: c t f 1$ and $\Delta c t f 2:: c t f 2$. Groups of 10 plants were inoculated by immersing the roots into a suspension of $5 \times 10^{6}$ freshly obtained microconidia per milliliter of the different strains and were planted in minipots. Survival percentage was recorded at different time points. All experiments were performed at least three times with similar results. The data shown are from one representative experiment.

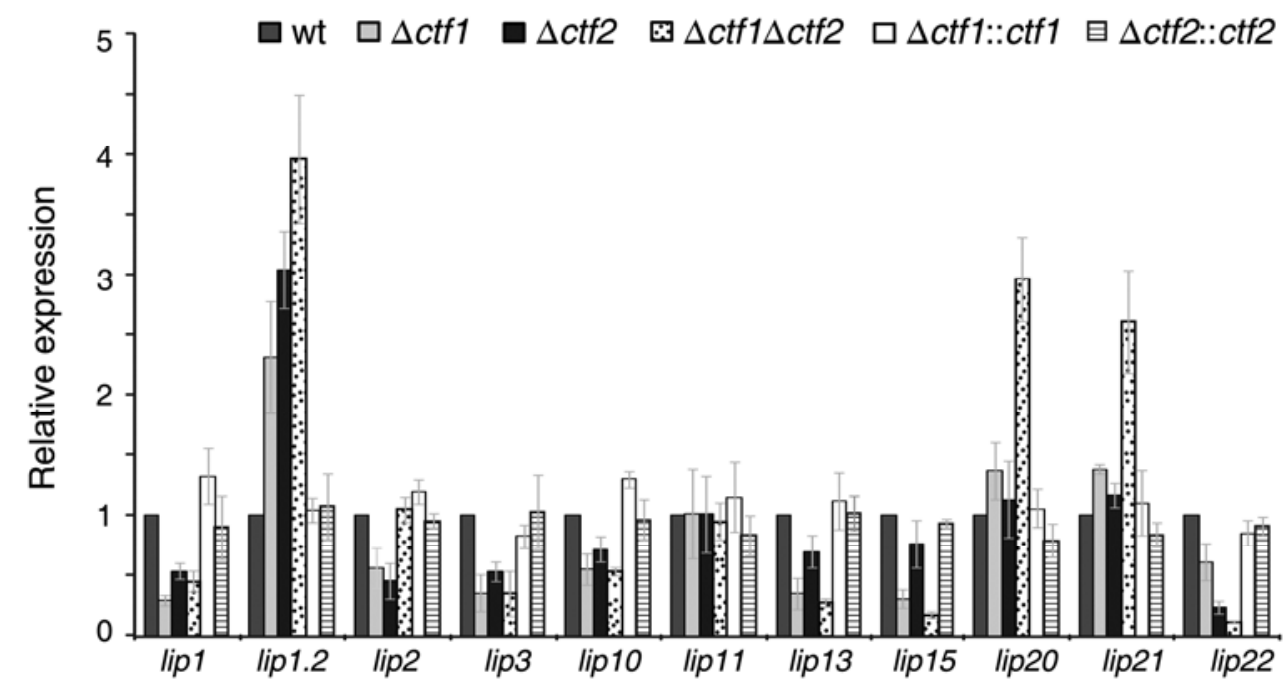

Fig. 8. Expression analysis of predicted structural lipase genes by quantitative reverse transcription-polymerase chain reaction in Fusarium oxysporum strains under wheat germ oil-induced conditions. Bars represent standard errors calculated from three biological replicates, each including three technical replicates. 
bootstrap phylogenetic analysis of the resulting alignment with the maximum likelihood method after optimization of the settings by the MODELGENERATOR program, version 0.85 (Keane et al. 2006). Phylogenetic relationships among sequences were depicted in phylogenetic trees constructed using $M E G A$ version 4 (Tamura et al. 2007).

\section{Fungal isolates and culture conditions.}

F. oxysporum f. sp. lycopersici wild-type strain 4287 (race 2) was obtained from J. Tello, Universidad de Almeria, Spain, and was stored at $-80^{\circ} \mathrm{C}$ with glycerol, as a microconidia suspension. The pathotype of the isolates was periodically confirmed by pathogenicity tests. For extraction of DNA and microconidia production, cultures were grown in potato dextrose broth (PDB) (Difco, Detroit) at $28^{\circ} \mathrm{C}$ as described previously (Di Pietro and Roncero 1998).

\section{Purification and biochemical characterization of lipases.}

All purification steps were carried out at $4^{\circ} \mathrm{C}$ unless otherwise stated. Fusarium germlings were collected from PDB cultures $14 \mathrm{~h}$ after inoculation and were transferred for induction to oneliter Erlenmeyer flasks containing $200 \mathrm{ml}$ of SM (Di Pietro and Roncero 1998) supplemented with $2 \%$ WGO. Cultures were maintained in a rotary shaker at $150 \mathrm{rpm}$ and $28^{\circ} \mathrm{C}$ for 18 to 20 h. Cultures were filtered through Monodur (pore size $0.45 \mu \mathrm{m}$ ) to discard mycelia. The filtrate was centrifuged to discard microconidia, and the supernatant was transferred to dialysis tubing (12 kDa cut-off), was dialyzed overnight against distilled water, and was concentrated fourfold by placing the tubing on solid polyethylene glycol (35 k Mr; Fluka Chemika-Biochemika, Buchs, Switzerland). The concentrate was then subject to preparative IEF on a Rotofor apparatus (BioRad, Munich). Preparative IEF was carried out in a total volume of $55 \mathrm{ml}$ containing $2 \%$ (wt/vol) carrier ampholytes (Bio-Lyte 3/10; BioRad) at $4^{\circ} \mathrm{C}$ for 3 to $6 \mathrm{~h}$ at $12 \mathrm{~W}$ constant power. Twenty fractions were collected and analyzed for lipase activity. The 20 fractions were mixed together four by four to obtain five different pools. These pools were transferred to dialysis tubing (12 kDa cut-off) after addition of $1 \mathrm{M} \mathrm{NaCl}$ final concentration, were dialyzed overnight against distilled water to eliminate the ampholytes, and were freeze-dried and concentrated 10-fold, using methanolchloroform (4:1). For total activity assays, culture supernatants of the wild-type and mutant strains collected under the conditions described above were concentrated 50-fold and were used as the enzyme source. In all cases, lipase activity was determined using as substrate pNPP (Sigma, St. Louis) (Winkler and Stuckman 1979). A $20-\mu l$ volume of supernatant was added to $230 \mu \mathrm{l}$ of reaction buffer containing $2 \mathrm{mM}$ pNPP in isopropanol, $1 \%$ gum arabic (Sigma), 0.1\% Triton X-100 (Merck, Amsterdam, The Netherlands), and $50 \mathrm{mM}$ bis-Tris-propane (Sigma), at $\mathrm{pH} 8$, and was incubated at $37^{\circ} \mathrm{C}$ for 15 to $30 \mathrm{~min}$. Production of p-nitrophenol in both assays was measured at $405 \mathrm{~nm}$ using a multi-well SpectraFluor Plus spectrophotometer. Each assay was carried out three times in 96-well microtiter plates. One unit of enzymatic activity was defined as $1 \mathrm{nM} \mathrm{min}{ }^{-1}$ p-nitrophenol released from the substrate. Calibration curves were made using standard p-nitrophenol solutions. Expression values are presented as relative to the wild-type strain, as indicated. SDSPAGE was performed in $12 \%$ discontinuous (wt/vol) acrylamide gels (BioRad, Hercules, CA, U.S.A.). Protein was determined according to the method of Bradford using the BioRad protein assay (BioRad) with bovine serum albumin as standard.

\section{Nucleic acid manipulation.}

Total RNA and genomic DNA were extracted from $F$. oxysporum mycelium, noninoculated, and inoculated tomato plants according to previously reported protocols (Chomzcynski and Sacchi 1987; Raeder and Broda 1985). Southern analyses and probe labeling were carried out as described previously (Di Pietro and Roncero 1998), using the nonisotopic digoxigenin labeling kit (Roche Applied Science, Indianapolis, IN, U.S.A.). Sequencing of DNA clones was performed at the Servicio de Secuenciación Automática de DNA, SCAI (University of Córdoba, Spain) using the Dyedeoxy terminator cycle sequencing kit (Applied Biosystems, Foster City, CA, U.S.A.) on an ABI Prism 377 Genetic Analyser apparatus (Applied Biosystems). DNA and protein sequence databases were searched using the BLAST algorithm (Altschul et al. 1990) at NCBI (Bethesda, MD, U.S.A.) or at Broad Institute Fusarium comparative database. PCR reactions were routinely performed with the High fidelity template PCR system (Roche Diagnostics, Mannheim, Germany).

\section{Targeted disruption of structural and regulatory lipase encoding genes.}

Targeted gene replacement was performed using the split marker technique (Catlett et al. 2003). For each transformation, two overlapping gene deletion constructs were used. One contained the promoter sequence of each target gene, obtained by amplification with a specific primer pair fused to the $3^{\prime}$ end (approximately 75\%) of the $\mathrm{Hyg}^{\mathrm{R}}$ cassette (Carroll et al. 1994), and the other fragment contained the terminator region of the target gene, obtained by amplification with a specific primer pair fused to the $5^{\prime}$ end (approximately $75 \%$ ) of the $\mathrm{Hyg}^{\mathrm{R}}$ cassette. For construction of the disruption mutants, the two overlapping DNA fragments were used to transform protoplasts of $F$. oxysporum wild-type strain 4287, as reported previously (Di Pietro and Roncero 1998). The resulting $\mathrm{Hyg}^{\mathrm{R}}$ putative transformants were initially identified by PCR (not shown), and the homologous as well as ectopic recombination events were confirmed by Southern analysis of selected transformants using promoter, terminator, or internal gene fragments as probes. Complementation of the single $\Delta c t f 1$ and $\Delta c t f 2$ mutants was achieved by reintroducing the $c t f 1$ or the $c t f 2$ wildtype allele into the $\Delta c t f 1$ or $\Delta c t f 2$, respectively, genetic background using the $\mathrm{Phl}^{\mathrm{R}}$ cassette (Punt and van den Hondel 1992) as selective marker. The double-targeted mutant $\Delta c t f 1 \Delta c t f 2$ was obtained by gene replacement of the ctfl allele on $\Delta c t f 2$ genetic background by the split marker technique, as described above, using the $\mathrm{Phl}^{\mathrm{R}}$ as selective marker.

\section{Gene expression analysis.}

Expression of $F$. oxysporum predicted lipase genes during plant colonization was analyzed by qRT-PCR. Ten tomato plants from each treatment were removed at several time periods from 2 to $192 \mathrm{~h}$ after inoculation. Total cDNA obtained from RNA isolated from roots and stems of noninoculated and inoculated plants was subjected to qRT-PCR, using the appropriate genespecific primer pair. Quality of extracted nucleic acids was verified by running aliquots in ethidium bromide-stained agarose gels $(0.7 \% \mathrm{wt} / \mathrm{vol}$ in Tris-acetate-EDTA buffer) and further visualized under UV light. Additionally, they were also quantified in a NanoDrop ND-1000 Spectrophotometer. The isolated RNA was treated with DNase I (Fermentas, Hanover, MD, U.S.A.) and was then used to synthesize cDNA, using ribonuclease inhibitor RNasin Plus RNase inhibitor (Promega, Madison, WI, U.S.A.) and M-MLV reverse transcriptase (Invitrogen, Carlsbad, CA, U.S.A), according to the manufacturer's instructions. Three simultaneous technical replicate amplifications were carried out for each cDNA sample. Amplification reactions were performed in 96-well microtiter plates (Bio-Rad), and each reaction was made up using aliquots from the same master mix. PCR assays were performed in an iCycler iQ real-time PCR system (Bio$\mathrm{Rad})$, using the following cycling protocol: an initial step of de- 
naturation $\left(5 \mathrm{~min}, 94^{\circ} \mathrm{C}\right)$ followed by 40 cycles of $30 \mathrm{~s}$ at $94^{\circ} \mathrm{C}$, $30 \mathrm{~s}$ at $62^{\circ} \mathrm{C}, 45 \mathrm{~s}$ at $72^{\circ} \mathrm{C}$, and $20 \mathrm{~s}$ at $80^{\circ} \mathrm{C}$ for measurement of the fluorescence emission. After this, a melting curve program was run, for which measurements were made at $0.5^{\circ} \mathrm{C}$ temperature increases every $5 \mathrm{~s}$ within a range of 55 to $95^{\circ} \mathrm{C}$. Relative levels of the RT-PCR products were determined using the cycle threshold ( $\Delta \Delta \mathrm{Ct}$ ) method (Livak and Schmittgen 2001). Ct values were normalized to the $\mathrm{Ct}$ value of the actin gene. Samples from noninoculated plants or without cDNA were used as negative control reactions. The assay was repeated three times with independent biological samples.

Expression of lipase genes during in vitro growth of Fusarium strains was analyzed by qRT-PCR, as described above. Total RNA was extracted from 18 to 20-h WGOinduced germlings, followed by cDNA synthesis. Expression values are presented as relative to those of wild-type strain and normalized to the $\mathrm{Ct}$ value of the actin gene. Samples without cDNA were used as negative control reactions.

\section{Phenotypic analysis of mutants.}

Vegetative growth of $F$. oxysporum lipase mutants was determined on plates of potato dextrose agar (Difco) or SM, containing one of the following carbon sources: $1 \%$ glucose, 50 $\mathrm{mM}$ sodium acetate, $2.5 \mathrm{mM}$ sodium oleate, $10 \mathrm{mM}$ sodium butyrate, $0.5 \%$ (wt/vol) glycerol trioleate, $0.5 \%$ (vol/vol) glycerol tributyrate, $0.5 \%$ ( vol/vol) glycerol tripalmitate, $2.5 \mathrm{mM}$ erucic acid, $0.5 \%$ (vol/vol) olive oil, or $0.5 \%$ (vol/vol) WGO. The media were emulsified using an Ultra-Turrax homogenizer (Ika, Königswinter, Germany) and were poured into petri dishes. Aliquots of $5 \mu \mathrm{l}$ of water containing 200 freshly obtained microconidia were spotted onto the agar plates and were incubated at $28^{\circ} \mathrm{C}$ for 6 days before being scanned.

Bikaverin production was visually assessed by spectrophotometric reading of absorbance at wavelengths 200 to $600 \mathrm{~nm}$ of WGO-induced culture supernatants from the different strains and compared with noninoculated WGO-medium. Further identification of this red pigment was performed at the Mass Spectrometry and Chromatography Unit of Universidad de Córdoba (Spain). The lipidic fractions were subjected to partitioning by three consecutive extractions with acetonitrile:hexane. The acetonitrile fraction was concentrated to $2 \mathrm{ml}$, and then, was separated by solid phase extraction with Florisil columns (1 g) to remove the oily residues from the samples, and was eluted with $15 \mathrm{ml}$ of acetonitrile. Finally, samples were dried in a Rotovap, were reconstituted with $1 \mathrm{ml}$ of methanol, and were then subjected to HPLC-MS for identification, using bikaverin purified solution provided by J. Avalos (Universidad de Sevilla, Spain) as standard. Samples obtained were analyzed by HPLC-MS using positive electrospray ionization mode (HPLC/MS Varian 1200L Triple Quadrupole). The ions formed in the ionization source were detected working in full-scan mode performing a scanning ion masses from m/z 150 to 800 (1-s scan scanning speed). Liquid chromatography was performed using a $\mathrm{C} 18$ reversed phase column $\left(15 \mathrm{~cm} \times 0.21 \mathrm{~mm}\right.$ ID) at a column temperature of $35^{\circ} \mathrm{C}$. The mobile phases used were water:formic acid $(0.1 \%)$ and methanol in gradient working mode.

\section{Pathogenicity tests.}

Root inoculation assays were performed as described previously (Di Pietro and Roncero 1998). Briefly, 14-day-old tomato seedlings (cv. Moneymaker, seeds provided by J. Cuartero, La Mayora-CSIC, Spain) were inoculated with $F$. oxysporum strains by immersing the roots in a suspension of $5 \times 10^{6}$ microconidia per microliter for $30 \mathrm{~min}$, were planted in vermiculite, and were maintained in a growth chamber at $28^{\circ} \mathrm{C}$ with 14 -h light daily photoperiod. Ten plants were used for each treatment. Number of dead plants was recorded daily for 35 days as previously de- scribed (López-Berges et al. 2012). Plant survival was calculated and compared among groups using the Mantel-Cox test. Data were analyzed with the software GraphPad Prism 4. All pathogenicity tests were performed at least three times with similar results.

\section{ACKNOWLEDGMENTS}

The authors gratefully acknowledge A. Di Pietro for valuable suggestions and critical reading of the manuscript, E. Martínez Aguilera for technical assistance (both from Universidad de Córdoba), and W. Schäfer (Universität Hamburg) for sequence sharing and helpful discussions. This research was supported by the Ministerio de Ciencia y Tecnología (BIO2010-015505) of Spain, and Junta de Andalucía (P08-CVI-3847). G. B. Ruiz had a Ph.D. fellowship from Junta de Andalucía (Spain) and spent six weeks stay at W. Schäfer's lab within the frame of a bilateral project (Acción Integrada Hispano-Germana HD2008-0072, Ministerio de Ciencia e Innovación).

\section{LITERATURE CITED}

Altschul, S. F., Gish, W., Miller, W., Myers, E. W., and Lipman, D. J. 1990. Basic local alignment search tool. J. Mol. Biol. 215:403-410.

Berto, P., Commenil, P., Belingheri. L., and Dehorter, B. 1999. Occurrence of a lipase in spores of Alternaria brassicicola with a crucial role in the infection of cauliflower leaves. FEMS (Fed. Eur. Microbiol. Soc.) Microbiol. Lett. 180:183-189.

Blow, D. 1992. Enzymology. More of the catalytic triad. Nature 343:694695.

Carroll, A. M., Sweigard, J. A., and Valent, B. 1994. Improved vectors for selecting resistance to hygromycin. Fungal Genet. Newsl. 41: 22.

Castresana, J. 2000. Selection of conserved blocks from multiple alignments for their use in phylogenetic analysis. Mol. Biol. Evol. 17:540-552.

Catlett, N. L., Lee, B.-N., Poder O. C., and Turgeon, G. 2003. Split-marker recombination for efficient targeted deletion of fungal genes. Fungal Genet. Newsl. 50:9-11.

Chahinian, H., Nini, L., Boitard, E., Dubès, J.-P., Comeau, L.-C., and Sarda, L. 2002. Distinction between esterases and lipases: A kinetic study with vinyl esters and TAG. Lipids 37:653-662.

Chomzcynski, P., and Sacchi, N. 1987. Single-step method of RNA isolation by acid guanidinium thiocyanatephenol- chloroform extraction. Anal. Biochem. 162:156-159.

Commenil, P., Belingheri, L., and Dehorter, B. 1998. Antilipase antibodies prevent infection of tomato leaves by Botrytis cinerea. Physiol. Mol. Plant Pathol. 52:1-14.

Commenil, P., Belingheri, L., Bauw, G., and Dehorter, B. 1999. Molecular characterization of a lipase induced in Botrytis cinerea by components of grape berry cuticle. Physiol. Mol. Plant Pathol. 55:37-43.

Devescovi, G., Bigirimana, J., Degrassi, G., Cabrio, L., LiPuma, J. J., Kim, J., Hwang, I., and Venturi, V. 2007. Involvement of a quorumsensing-regulated lipase secreted by a clinical isolate of Burkholderia glumae in severe disease symptoms in rice. Appl. Environ. Microbiol. 73:4950-4958.

Di Pietro, A., and Roncero, M. I. G. 1998. Cloning, expression, and role in pathogenicity of $p g l$ encoding the major extracellular endopolygalacturonase of the vascular wilt pathogen Fusarium oxysporum. Mol Plant-Microbe Interact. 11:91-98.

Di Pietro, A., Madrid, M. P., Caracuel, Z., Delgado-Jarana, J., and Roncero, M. I. G. 2003. Fusarium oxysporum: Exploring the molecular arsenal of a vascular wilt fungus. Mol. Plant Pathol. 4:315-326.

Di Pietro, A., Roncero, M. I. G., and Ruiz-Roldán M. C. 2009. From tools of survival to weapons of destruction: The role of cell wall-degrading enzymes in plant infection. In: Plant Relationships, 2nd ed. The Mycota V. H. Deising, ed. Springer-Verlag, Berlin.

Dickman, M. B., Podila, G. K., and Kolattukudy, P. E. 1989. Insertion of cutinase gene into a wound pathogen enables it to infect intact host. Nature 342:446-448.

Feng, J., Liu G, Selvaraj, G., Hughes, G. R., and Wei, Y. 2005. A secreted lipase encoded by LIP1 is necessary for efficient use of saturated triglyceride lipids in Fusarium graminearum. Microbiology 151:3911-3921.

Fischer, M., and Pleiss, J. 2003. The lipase engineering database: A navigation and analysis tool for protein families. Nucleic Acids Research 31:319-321.

García-Maceira, F. I., Di Pietro, A., and Roncero, M. I. G. 2000. Cloning and disruption of pgx4 encoding an in planta-expressed exopolygalacturonase from Fusarium oxysporum. Mol. Plant-Microbe Interact.13:359-365.

García-Maceira, F. I., Di Pietro, A., Huertas-González, M. D., RuizRoldán, M. C., and Roncero, M. I. G. 2001. Molecular characterization of an endopolygalacturonase from Fusarium oxysporum expressed dur- 
ing early stages of infection. Appl. Environ. Microbiol. 67:2191-2196.

Gómez-Gómez, E., Roncero, M. I. G., Di Pietro, A., and Hera, C. 2001. Molecular characterization of a novel endo-beta-1,4-xylanase gene from the vascular wilt fungus Fusarium oxysporum. Curr. Genet. 40:268-275.

Gómez-Gómez, E., Ruiz-Roldán, M. C., Di Pietro, A., Roncero, M. I. G., and Hera, C. 2002. Role in pathogenesis of two endo-beta-1,4-xylanase genes from the vascular wilt fungus Fusarium oxysporum. Fungal Genet. Biol. 35:213-222.

Guindon, S., and Gascuel, O. 2003. A simple, fast, and accurate algorithm to estimate large phylogenies by maximum like-hood. Syst. Biol. 52:696-704

Hall, T. A. 1999. BioEdit: A user-friendly biological sequence alignment editor and analysis program for Windows 95/98/NT. Nucleic Acids Symp. Ser. 41:95-98.

Hube, B., Stehr, F., Bossenz, M., Mazur, A., Kretschmar, M., and Schäfer, W. 2000. Secreted lipases of Candida albicans: Cloning, characterization and expression analysis of a new gene family with at least ten members. Arch. Microbiol. 174 :362-374.

Huertas-González, M. D., Ruiz-Roldán, M. C., García Maceira, F. I., Roncero, M. I., and Di Pietro, A. 1999. Cloning and characterization of pll encoding an in planta-secreted pectate lyase of Fusarium oxysporum. Curr. Genet. 35:36-40.

Hynes, M. J., Murray, S. L., Duncan, A., Khew, G. S., and Davis, M. A 2006. Regulatory genes controlling fatty acid catabolism and peroxisomal functions in the filamentous fungus Aspergillus nidulans. Eukaryot. Cell 5:794-805.

Jaeger, K. E., and Eggert, T. 2002. Lipases for biotechnology. Curr. Opin. Biotechnol.13:390-397.

Keane, T. M., Creevey, C. J., Pentony, M. M., Naughton, T. J., and McInerney, J. O. 2006. Assessment of methods for amino acid matrix selection and their use on empirical data shows that ad hoc assumptions for choice of matrix are not justified. BMC Evol. Biol. 6:12-29.

Li, D., and Kolattukudy, P. E. 1997. Cloning of cutinase transcription factor 1, a transactivating protein containing $\mathrm{Cys}_{6} \mathrm{Zn}_{2}$ binuclear cluster DNA binding motif. J. Biol. Chem. 272:12462-12467.

Li, D., Sirakova, T., Rogers, L., Ettinger, W., and Kolattukudy, P. E. 2002. Regulation of constitutively expressed and induced cutinase genes by different zinc finger transcription factors in Fusarium solani f. sp. pisi (Nectria haematococca). J. Biol. Chem. 277:7905-7912.

Liang, S. D., Marmorstein, R., Harrison, S. C., and Ptashne, M. 1996. DNA sequence preferences of GAL4 and PPR1: How a subset of $\mathrm{Zn}_{2} \mathrm{Cys}_{6}$ binuclear cluster proteins recognizes DNA. Mol. Cell. Biol. 16:3773-3780.

Limón, M. C., Rodríguez-Ortiz, R., and Avalos, J. 2010. Bikaverin production and applications. Appl. Microbiol. Biotechnol. 87:21-29.

Livak, K. J., and Schmittgen, T. D. 2001. Analysis of relative gene expression data using real-time PCR and the 2- $\left(\Delta \Delta \mathrm{C}_{\mathrm{T}}\right)$ method. Methods 25:402-408.

López-Berges, M. S., Capilla, J., Turrà, D., Schafferer, L., Matthijs, S., Jöchl, C., Cornelis, P., Guarro, J., Haas, H., and Di Pietro, A. 2012. HapX-mediated iron homeostasis is essential for rhizosphere competence and virulence of the soilborne pathogen Fusarium oxysporum. Plant Cell 24:3805-3822.

Lowe, M. E. 1992. The catalytic site residues and interfacial binding of human pancreatic lipase. J. Biol. Chem. 267:17069-17073.

Ma, L. J., van der Does, C., Borkovich, K. A., Coleman, J. J., Daboussi, M. J., Di Pietro, A., Dufresne, M., Freitag, M., Grabherr, M., Henrissat. B., Houterman, P. M., Kang, S., Shim, W. B., Woloshuk, C., Xie, X., $\mathrm{Xu}$, J. R., Antonxiw, J., Baker, S. E., Bluhm, B. H., Breakspear, A., Brown, D. W., Butchko, R. A. E., Chapman, S., Coulson, R., Coutinho, P. M., Danchin, E. G. J., Diener, A., Gale, L. R., Gardiner, D. M., Goff. S., Hammond-Kosack, K. E., Hilburn, K., Houterman, P. M., Hua-Van, A., Jonkers, W., Kazan, K., Kodira, C. D., Koehrsen, M., Kumar, L., Lee, Y. H., Li, L., Manners, J. M., Miranda-Saavedra, D., Mukherjee, M., Park, G., Park, J., Park, S. Y., Proctor, R. H., Regev, A., RuizRoldán, M. C., Sain, D., Sakthikumar, S., Sykes, S., Schwartz, D. C., Turgeon, B. G., Wapinski, I., Yoder, O., Young, S., Zeng, Q., Zhou, S., Galagan, J., Cuomo, C. A., and Kistler, H. C., and Rep, M. 2010. Comparative genomics reveals mobile pathogenicity chromosomes in Fusarium oxysporum. Nature 464:367-73.

Martínez-Rocha, A.-L., Di Pietro, A., Ruiz-Roldán M. C., and Roncero, M. I. G. 2008. Ctf1, a transcriptional activator of cutinase and lipase genes in Fusarium oxysporum is dispensable for virulence. Mol. Plant Pathol. 9:293-304.

Nardini, M., and Dijkstra, B. W. 1999. Alpha/beta hydrolase fold enzymes: The family keeps growing. Curr. Opin. Struct. Biol. 9:732-737.

Nasser Eddine, A., Hannemann, F., and Schäfer, W. 2001. Cloning and ex- pression analysis of $N h L 1$, a gene encoding an extracellular lipase from the fungal pea pathogen Nectria haematococca MP VI (Fusarium solani f. sp. pisi) that is expressed in planta. Mol. Genet. Genomics 265:215-224.

Nguyen, L.-N., Dao, T. T., Zivkovíc, T., Fehrholz, M., Schäfer, W., and Salomon, S. 2010. Enzymatic properties and expression patterns of five extracellular lipases of Fusarium graminearum in vitro. Enzyme Microb.Technol. 46:479-486.

Novotnyy, C., and Dolezalová, L. 1993. Effect of lipids and detergents on the production and solubilization of extracellular lipase in Yarrowia lipolytica. Folia Microbiol. 38:49-54.

Paper, J. M., Scott-Craig, J. S., Adhikari, N. D., Cuomo, C. A., and Walton, J. D. 2007. Comparative proteomics of extracellular proteins in vitro and in planta from the pathogenic fungus Fusarium graminearum. Proteomics 7:3171-3183.

Punt, P. J., and van den Hondel, C. A., 1992. Transformation of filamentous fungi based on hygromycin B and phleomycin resistance markers. Methods Enzymol. 216:447-457.

Raeder, U., and Broda, P. 1985. Rapid preparation of DNA from filamentous fungi. Lett. Appl. Microbiol. 1:17-20.

Reis, H., Pfiffi, S., and Hahn, M. 2005. Molecular and functional characterization of a secreted lipase from Botrytis cinerea. Mol. Plant Pathol. 6:257-267.

Rogers, L. M., Flaishman, M. A., and Kolattukudy, P. E. 1994. Cutinase gene disruption in Fusarium solani f. sp pisi decreases its virulence on pea. Plant Cell 6:935-945.

Ruiz, M. C., Di Pietro, A., and Roncero, M. I. G. 1997. Purification and characterization of an acidic endo- $\beta$-1,4-xylanase from the tomato vascular pathogen Fusarium oxysporum f. sp. lycopersici. FEMS (Fed. Eur. Microbiol. Soc.) Microbiol. Lett.148:75-82.

Ruiz-Roldán, M. C., Di Pietro, A., Huertas-González, M. D., and Roncero, M. I. G. 1999. Two xylanase genes of the vascular wilt pathogen Fusarium oxysporum are differentially expressed during infection of tomato plants. Mol. Gen. Genet. 261:530-536.

Salomon, S., Gácser, A., Frerichmann, S., Kröger, C., Schäfer, W., and Voigt, C. A. 2012. The secreted lipase FGL1 is sufficient to restore the initial infection step to the a pathogenic Fusarium graminearum MAP kinase disruption mutant $\Delta$ gpmkl. Eur. J. Plant Pathol. 134:23-37.

Shen, W. J., Patel, S., Natu, V., and Kraemer, F. B. 1998. Mutational analysis of structural features of rat hormone-sensitive lipase. Biochemistry 37:8973-8979.

Son, S. W.,Kim, H. Y., Choi, G. J. Lim, H. K.,Jang, K. S. Lee, S. O.,Lee, S., Sung, N. D., and Kim, J. C. 2008. Bikaverin and fusaric acid from Fusarium oxysporum show anti-oomycete activity against Phytophthora infestans. J. Appl. Microbiol. 104:692-698.

Tamura, K., Dudley, J., Nei, M., and Kumar, S. 2007. MEGA4: Molecular Evolutionary analysis (MEGA4) software version 4.0. Mol. Biol. Evol. 24:1596-1599.

Thompson, J. D., Higgins, D. G., and Gibson, T. J.1994. Clustal W improving the sensitivity of progressive multiple sequence alignment through sequence weighting, position-specific gap penalties and weight matrix choice. Nucleic Acids Res. 22:4673-4680.

Voigt, C. A., Schäfer, W., and Salomon, S. 2005. A secreted lipase of Fusarium graminearum is a virulence factor required for infection of cereals. The Plant J. 42:364-375.

Walton, J. D. 1994. Deconstructing the plant cell wall. Plant Physiol. 104:1113-1118

Wiemann, P., Willmann, A., Straeten, M., Kleigrewe, K., Beyer, M., Humpf, H.-U., and Tudzynski, B. 2009. Biosynthesis of the red pigment bikaverin in Fusarium fujikuroi: genes, their function and regulation. Mol. Microbiol. 72:931-946.

Wiemann, P., Brown, D. W., Kleigrewe, K., Bok, J. W., Keller, N. P., Humpf, H. U., and Tudzynski, B. 2010. FfVel1 and FfLae1, components of a velvet-like complex in Fusarium fujikuroi, affect differentiation, secondary metabolism and virulence. Mol. Microbiol. 77:972-994.

Winkler, U. K., and Stuckman, M. 1979. Glycogen, hyaluronate, and some other polysaccharides greatly enhance the formation of exolipase by Serratia marcescens. J. Bacteriol.138:663-679.

Woloshuk, C. P., and Kolattukudy, P. E. 1986. Mechanism by which contact with plant cuticle triggers cutinase gene expression in the spores of Fusarium solani f. sp. pisi. Proc. Natl. Acad. Sci. USA 83:1704-1708.

\section{AUTHOR-RECOMMENDED INTERNET RESOURCES}

Broad Institute website: www.broadinstitute.org

Scansite molecular weight and isoelectric point calculator: scansite.mit.edu/calc_mw_pi.html 